Check for updates

Cite this: Mater. Adv., 2022, 3,2337

Received 31st October 2021, Accepted 26th January 2022

DOI: $10.1039 / \mathrm{d} 1 \mathrm{ma} 01012 \mathrm{c}$

rsc.li/materials-advances

\section{Electro-responsive polymer-based platforms for electrostimulation of cells}

\begin{abstract}
Akel Ferreira Kanaan and Ana Paula Piedade (D)*
Tissue engineering is a fascinating branch of science that aims to develop strategies to respond to tissue/ organ damage with the slightest biological rejection. It is currently known that electric cues can trigger several cell metabolic responses such as differentiation, proliferation, growth, attachment, alignment, and apoptosis. Electro-responsive polymer-based materials are considered one of the most appropriate classes of materials for developing advanced conducting systems that can fulfill this purpose. These materials act as conducting platforms that can properly transmit electrical signals to cells and work as a physical environment to ensure cell nutrition and development. The motivation of this review is to summarize the recent work in terms of polymer-based conducting scaffolds for electro-assisted cell culture. An overview of the most commonly studied polymers and scaffold design methodologies is presented. Moreover, the mechanisms behind the effect of electric cues on cell fate are briefly described. Finally, the conclusions and future perspectives regarding conducting polymer-based scaffolds for tissue engineering are also given.
\end{abstract}

\section{Introduction}

Stimuli-responsive materials, also known as "smart" materials, have been mainly utilized to design several advanced systems, namely sensors, actuators, robotics, electrochromic devices, and controlled/sustained drug delivery, which attempt to contemplate the specific and vast array of necessities of our current society. Among the family of "smart" materials, electroresponsive ones are currently being investigated to design advanced electro-conductive scaffolds for noble applications as cell culture/tissue engineering platforms. ${ }^{1-3}$

CEMMPRE, Department of Mechanical Engineering, University of Coimbra, 3030788 Coimbra, Portugal. E-mail: ana.piedade@dem.uc.pt
These materials allow the communication of exogenous applied electrical stimulation (ES), a recent physical methodology to trigger/induce the complex cell process cascades, with living cells to enhance cell-to-cell and/or cell-to-scaffold interactions. Moreover, these electro-responsive scaffolds also provide a suitable and adequate environment for developing several tissues, including bone, muscle, and neural networks. ${ }^{4}$ The development of these tissues is pivotal in regenerative medicine approaches for tissue repair/replacement of damaged sites.

Several polymers have been utilized in the development of electro-responsive scaffolds. Careful selection of the chemical nature of the scaffold's constituent polymer and its physicochemical properties (e.g., porous volume, swelling water

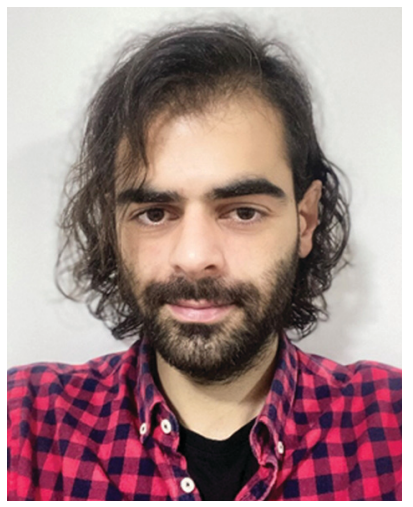

Akel Ferreira Kanaan completed his $P h D$ in Chemical Engineering at the University of Coimbra in 2021. He is currently working as a research fellow in the Department of Mechanical Engineering at the University of Coimbra. His professional interests and expertise are $3 D$ to $4 D$ printing materials, "smart" polymers, electroresponsive materials, and polymer functionalization.
Akel Ferreira Kanaan

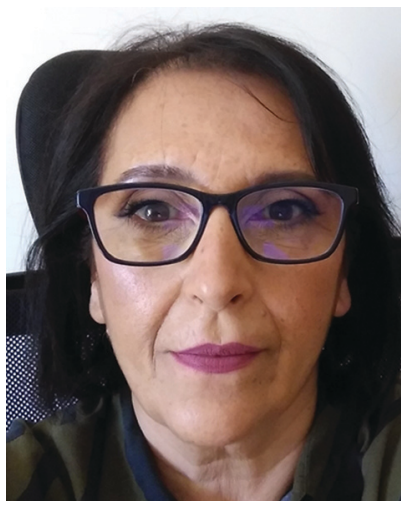

Ana Paula Piedade
Ana Paula Piedade obtained her BSC degree in Biochemistry, MSc degree in Cellular Biology and $P h D$ in Mechanical Engineering. She is currently an Assistant Professor with Habilitation in the Department of Mechanical Engineering at the University of Coimbra. Her professional interests and expertise are $3 D$ to $4 D$ printing, abiotic/biotic interfaces, biomedical invasive devices, prokaryotic cells as "living tools" and sustainable processing technologies. 
capacity, charge density, and topography) can significantly influence the overall characteristics of the final tissue. Additionally, other factors such as the intensity and magnitude of applied exogenous ES, type of cell line, and scaffold development strategy also play an important role in the cell's activities. $^{4,5}$ The current challenge is to engineer a suitable scaffold that satisfies specific requirements that induce a desired cell response in complex environments (e.g., in vivo) at physiological applied electrical potentials and also present biodegradability and biocompatibility without compromising its performance.

This review focuses on the description of recent electroresponsive polymer-based scaffolds for tissue engineering applications. The objective is to demonstrate an array of electro-responsive polymer-based materials that have been employed in the development of advanced scaffolds for electro-assisted cell culture. Additionally, a brief description of the mechanisms behind the cell's responses to ES is presented. Finally, the future trends regarding electro-responsive polymer-based tissue engineering scaffolds and their limitations and current challenges are also highlighted.

\section{Tissue engineering scaffolds: the influence of fabrication technologies and physicochemical cues on cell fate}

Several types of technologies are explored to develop conductive tissue engineering scaffolds, which include (but are not restricted to) electrospinning, solvent casting, lyophilisation, self-assembly, and micropatterning. ${ }^{4,6,7}$ The former is undoubtedly the most studied approach to obtain scaffolds due to the possibility of producing materials with oriented/organized nanofibrous pattern pathways that resemble natural extracellular matrix (ECM) structures.

Electrospinning is the most conventional fabrication method studied for obtaining tissue engineering scaffolds. This technology consists of forming polymer-based fibres in the submicron or microscale (fibre diameter $<1 \mu \mathrm{m}$ or $>1 \mu \mathrm{m}$, respectively) through the application of strong electric potentials $(\sim 20 \mathrm{kV})$. A classical electrospinning apparatus consists of a high voltage (DC or AC) power supply, a syringe pump, and a collector (Fig. 1). ${ }^{8}$ Briefly, the syringe is filled with a polymer solution or melt, and it is held at the capillary's tip due to surface tension forces. High electrical potentials are established between the syringe (usually positively charged) and the collector (either oppositely charged or grounded). Once the electrical input is given, electrostatic repulsions occur among the polymeric chains in the polymer solution. Thus, polymer solution drops assume a cone-shape format (so-called "Taylor cone") ${ }^{9}$ due to the accumulation of charges in the polymer solution or melt at the syringe's tip. ${ }^{6,8}$ By augmenting the magnitude of applied electrical stimulus, electrostatic repulsion forces surpass the surface tension of the polymer solution resulting in the formation of a jet. The jet travels towards the oppositely charged collector at a controlled rate provided by the syringe pump. In

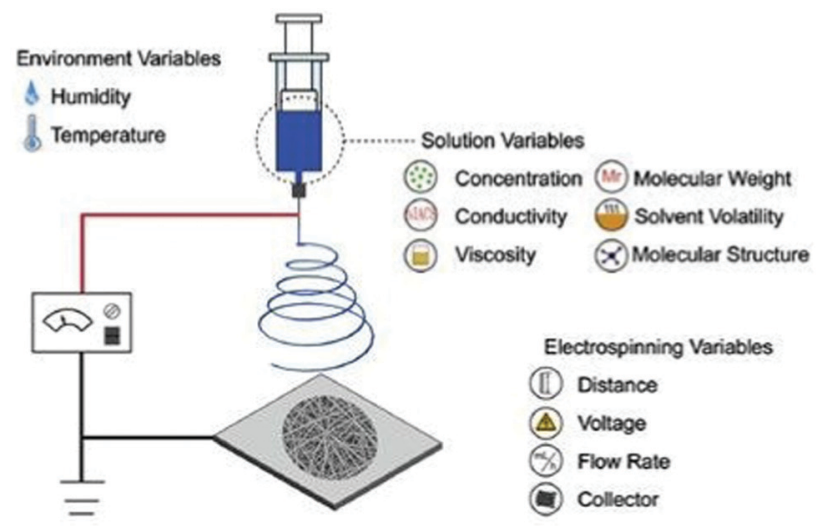

Fig. 1 Illustration of a conventional electrospinning apparatus for scaffold design and general parameters that can tune the physicochemical properties of the final electrospun mat. Reprinted from ref. 10, Copyright 2019 Elsevier.

this process, most of the solvent is evaporated before depositing onto the collector in a fibre-like matrix structure. Due to the spiral/whipping motion (also known as bending instability), the deposited fibre mats are randomly oriented.

The application of high electrical potentials leads to great plastic deformation of the polymer solution or melt. Consequently, the bending instability stretches the jet size (at least $1000 \times$ ), resulting in very long thin fibers. ${ }^{8,11}$ Finally, several parameters such as viscosity, surface tension and chemical nature of the polymer, the magnitude of applied electrical stimulus, and distance between the syringe's tip and collector can be used to tune the physicochemical properties of the obtained fibres (Fig. 1). ${ }^{10}$

To shorten the production rate time of electrospun fibres, different electrospinning configurations are presented as an alternative to the classical needle-syringe setup, namely the rotating cylindrical electrode and collector, wire electrode, and multichannel needles with a rotating cylindrical collector. ${ }^{8}$

Additive manufacturing (AM) technologies such as fused filament fabrication (FFF), bioprinting, and inkjet printing have been regarded as emergent methods to obtain electroresponsive scaffolds with a defined intricate architecture and shape. ${ }^{4,12}$ AM technologies allow precise tuning of printing parameters and, thus, higher control over physical properties/characteristics of the final material. Therefore, the obtained scaffolds are expected to have enhanced reproducibility, which can be regarded as an advantage over conventional electrospinning technologies. Electro-responsive polymer-based materials developed by $3 \mathrm{D}$ printing technologies are still in their infancy. ${ }^{13}$ Consequently, electroresponsive scaffolds obtained by AM technologies can be considered a new and less explored research area regarding advanced platforms for tissue engineering applications.

As defined, a scaffold is a support material that can adequately host and accommodate living organisms (e.g. cells) and ensure transport of nutrients and metabolites to promote their natural behaviour. Therefore, it is crucial to pre-determine the physicochemical properties of the scaffold platform in order to control the cell fate during cell culture. 


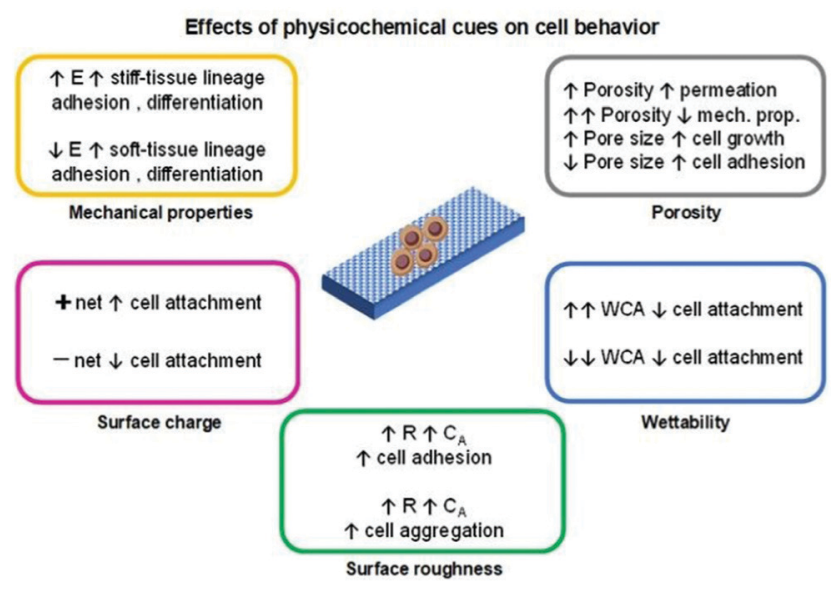

Fig. 2 Summary of commonly observed physicochemical cues on cell metabolic activity. Variables were coded as: elastic moduli $(E)$, water contact angle (WCA), surface roughness (R) and contact area (CA).

The technology employed for the development of a scaffold can determine its physicochemical properties and thus regulate the cell fate which is an essential factor when tissue engineering applications are envisaged. The physicochemical cues of a scaffold such as porosity, mechanical properties (stiffness), topography/roughness, wettability, and surface charge are variables that can influence the cell's biological responses (Fig. 2). ${ }^{4,14-16}$ The conjugation of these variables is mandatory to resemble the complex nature of the ECM.

Among the mentioned cues, the porosity (pore density, volume, size, and shape) is one of the most important and studied variables regarding cell behaviour influence for tissue engineering applications. In general, the porosity parameter plays a significant role in cell growth, adhesion and migration behaviour, nutrition exchange inside the scaffold, and the mechanical properties of the scaffold. ${ }^{4,14}$

Generally, the pore diameter of a scaffold (micrometric scale) is directly related to cell growth and adhesion. Larger pores induce cell migration from the outer layers towards the inner layer of the scaffold. With smaller pore diameters, enhanced cell adhesion is observed due to a higher specific area that prompts greater cell attachment. When the pore size is much higher than the size of the cells, their growth profile is similar to that observed in flat surfaces.

It is complicated to establish an optimal pore size for a widespread application because different cell behaviours are observed for distinct cell lines. Additionally, it is also essential to consider a suitable pore size according to the test environment (e.g., in vitro or in vivo). ${ }^{14}$ Nevertheless, most tissue engineering scaffolds present a broad pore size range of $100-500 \mu \mathrm{m} .{ }^{4}$

The pore connection and morphology also influence the cell behaviour. Highly porous platforms with interconnected cavities are interesting to promote and ensure the transport of nutrients and oxygen to cells and thus stimulate their growth.

A porosity of $96.7 \%$ is considered to be an optimal value to guarantee proper permeability. However, by augmenting the porosity, poorer mechanical properties of the scaffolds are attained. ${ }^{4}$ One strategy to overcome this drawback is by altering the pore geometry of the scaffold. The mechanical strength increases according to the following trend: diagonal $>$ stagger $>$ lattice. ${ }^{14}$ Nevertheless, the complexity of the pore geometry should not interfere with the metabolic activities of cells.

The mechanical properties of the scaffold (e.g., stiffness) are another important factor in regulating the cell fate. Living cells can respond to external mechanical stimulation and transduce this information into electrical and biochemical signals, which results in different cell differentiation, growth, migration, and adhesion. Cell lines that give origin to soft $(<100 \mathrm{kPa}$; brain, and muscle) or rigid/stiff ( $>1 \mathrm{MPa}$; cartilage, and bone $)^{17}$ tissue present enhanced adhesion on soft or stiff scaffolds, respectively. The differentiation behaviour of these cells follows the same trend, as cells seeded on soft/stiff scaffolds tend to differentiate into soft/stiff tissues, respectively. ${ }^{15,17}$

The topography and roughness of the scaffold also influence the behaviour of cells. Generally, by increasing the surface roughness, a higher contact area is obtained that promotes protein adsorption and, thus enhances the cell-protein-scaffold interactions resulting in greater adhesion/attachment. ${ }^{13}$ Moreover, cells tend to aggregate and form composite layers when seeded on rougher surfaces than in smoother ones. ${ }^{3}$ These composite layers prompt higher cell-cell signalling which ultimately enhances differentiation.

The wettability of a given scaffold for cell culture is a crucial and simple parameter to correlate the cell behaviour with scaffold characteristics. In general, superhydrophobic or superhydrophilic materials tend to present low/poor cell attachment/adhesion. This conduct is due to weak protein-scaffold forces, resulting in poor protein-meditated cell-scaffold interaction and, subsequently, a reduced cell attachment. Moderate water contact angle and surface energy values (for example, $\sim 85^{\circ}$ and $\sim 70 \mathrm{~mJ} \mathrm{~m}^{-2}$, respectively) are considered to be the optimal conditions to induce cell attachment, growth, and proliferation. ${ }^{15,18}$

When considering electro-responsive polymers for the design of tissue engineering scaffolds, the effect of the surface charge of these materials is relevant in determining the cell fate. Besides the aforementioned interactions (such as hydrophobic/hydrophilic, and physisorption), the electrostatic ones are also responsible for inducing cell activities. Generally, cells bear a negative net charge that favours electrostatic interactions with positively charged scaffolds resulting in higher cell adhesion and growth. Conversely, a poor cell-scaffold interaction is observed when negatively charged surfaces are employed due to cell-scaffold electrostatic repulsion. ${ }^{15,19}$

\section{Electrostimulation of cells: influence of electrical cues on cell functions}

Among the types of physicochemical cues mentioned earlier, ES is another factor that can be used to manipulate cell behaviour (in vitro and in vivo) and also promote/enhance tissue repair. $^{20-26}$ This process may be regarded as a potential 
alternative to commonly employed cell growth factors in the field of tissue engineering and regenerative medicine. ${ }^{5}$

There are several methods to deliver ES onto cells, namely direct electrode contact, capacitive stimulation, inductive/electromagnetic stimulation (EMS), and conductive scaffoldmediated ES (Fig. 3). ${ }^{5,20,23,27}$

The direct electrode contact method, also known as direct coupling, is the primarily employed method for cell ES due to its simplicity and convenience (Fig. 3A).

It consists of a pair of electrodes (e.g., $\mathrm{Ag} / \mathrm{AgCl}, \mathrm{Pt}$, or $\mathrm{Cu})$ submerged in a cell culture medium (highly conductive electrolyte solution) containing the cells and connected to a given power supply. Exogenous electrical fields utilized in this configuration are in the range of $10^{1}-10^{2} \mathrm{mV} \mathrm{mm}{ }^{-1} .^{20}$ The advantages associated with this methodology include multiwell stimulation and excellent reproducibility.

Nevertheless, it presents some disadvantages that are intrinsic to electrode-based systems, such as alteration of $\mathrm{pH}$ at the vicinities of electrodes ( $\mathrm{pH}$ waves), formation of cytotoxic faradaic by-products on the surface of the working electrodes, and electrophoresis (mass transport) of the components in the complex cell culture medium. Moreover, water electrolysis can also occur when the applied voltage between electrodes is higher than water's potential of $1.23 \mathrm{~V}$. In this case, frequent culture medium replenishing is often performed to attenuate the potential change in medium composition.

One strategy to overcome this problem is by direct coupling through salt bridges. The salt bridge-mediated ES avoids the formation of cytotoxic components, which result from redox reactions at the surface of the electrode in contact with the cell culture medium. Consequently, minimal culture medium

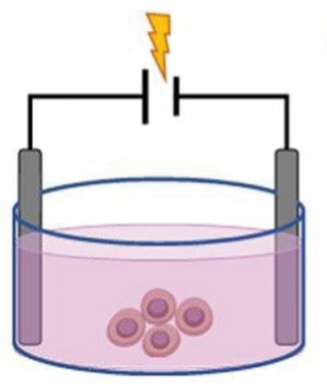

A)
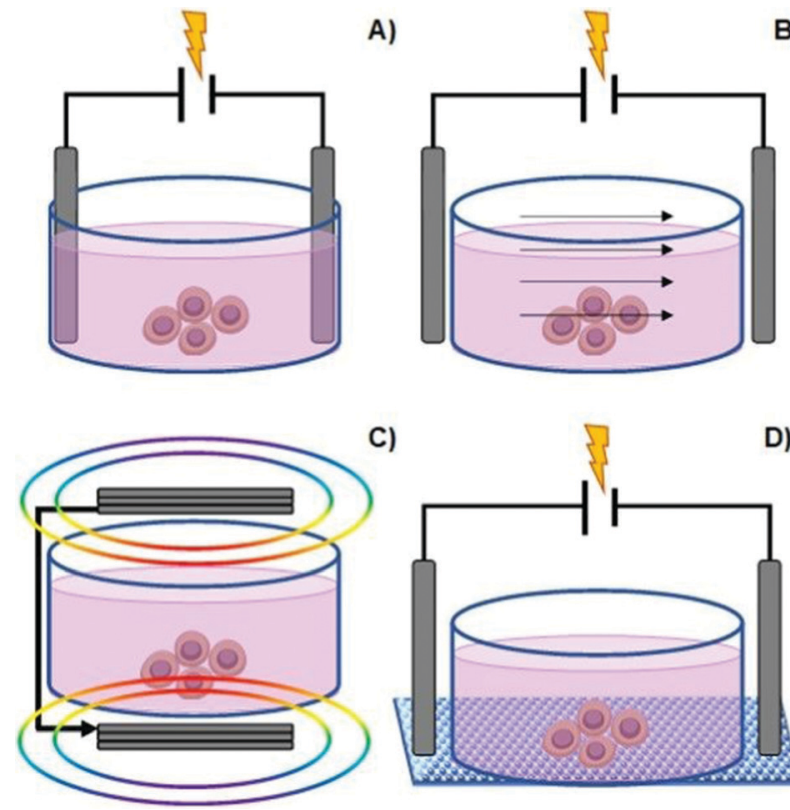

C)

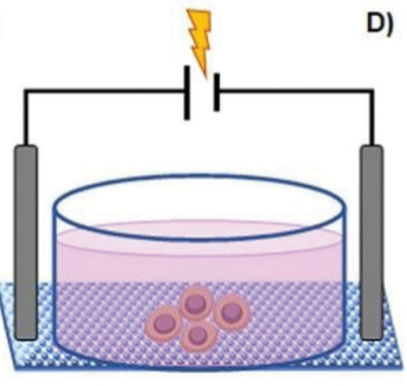

Fig. 3 Common methods to manipulate culture cells in vitro: direct contact (A), capacitive stimulation (B), electromagnetic induction (C) and conductive substrate-mediated ES (D). composition perturbation occurs. Salt-bridges for ES of cells are regularly composed of a polysaccharide (usually Agar) hydrogel loaded with electrolytes (e.g., $\mathrm{KCl}, \mathrm{KNO}_{3}$, or $\mathrm{NaClO}_{4}$ ). This approach also has drawbacks, including a higher circuit resistance (compared to direct coupling), reduced working area, complex experimental setup, and concentration gradients between the bridge contents and the electrolyte media, resulting in limited ES exposure time., ${ }^{5,20}$

Capacitive stimulation (Fig. 3B) is a non-invasive ES method to induce cell metabolic activities. The experimental apparatus consists of placing electrodes outside the cell culture medium to guarantee indirect contact. Thus, a given insulator is mounted between the electrode and the culture medium. Finally, by applying ES, an electrical field is obtained, which further induces polarization of the components in the cell culture medium (such as the cell membrane, water molecules, and proteins). The advantage of this system is that it avoids the drawbacks associated with electrode-based ES. Moreover, it allows a homogenous particle redistribution to all cells (electrophoretic mass transfer) due to the perpendicular electrical field to the culture plate established between electrodes. The associated drawback with the capacitive ES approach consists of providing high-voltage power sources in order to overcome the natural high impedance of the insulator material required for this system. . $23,27^{2}$

Another non-invasive strategy is the inductive EMS (Fig. 3C). An electric current passes through coiled electrodes (placed around the cell culture medium), where uniform electromagnetic fields are obtained. This uniform EMS is attained due to the specific spatial configuration of the electrodes that present an electrode-electrode distance equal to their radius (Helmholtz configuration). ${ }^{28}$ As an indirect method, EMS provides the stimulus potential near the target cell instead of direct ES, as mentioned for the electrode-based approach. The disadvantage of this method is great time and resource consumption. ${ }^{5,23,27}$

Finally, another type of non-invasive cell ES is given by the conductive scaffold-mediation (Fig. 3D). The cells "feel" the ES indirectly by its contact with the charged surface of the conductive scaffold. This approach comprises a conductive polymer-based scaffold sandwiched between the chamber (containing the cell culture medium) and an insulator material to avoid liquid leakage from the culture medium. Thus, the tip ends of the scaffold (that remained outside the culture medium) are connected to a power source to promote electrical stimulation to previously seeded cells. In this case, the electrical current is transmitted directly to the cells by the scaffold instead of to the culture medium. The advantage of this method is that the typical drawbacks associated with electrode-based systems are avoided by utilizing scaffolds with different physicochemical and mechanical properties and complex surface geometries.

Moreover, the ES-scaffold-cell synergy allows the evaluation of the effect of conductive scaffold properties in the cell's fate under electrical potential. Depending on the chemical nature of the polymer-based scaffold, several disadvantages are associated with this approach. The most common disadvantages 
are the instability of polymer-based scaffolds in aqueous culture medium, low biocompatibility and high cytotoxicity of the scaffold, limited attachment of the cells to the scaffold, significant impedance, and low surface wettability of the conductive substrate. ${ }^{5}$

Bioelectricity, also called endogenous ES, is defined as the electrical currents and potentials naturally produced by living organisms. Bioelectric currents are produced by the transport/flux of electrolytes across the cellular membrane and through tissues at a physiological magnitude range of $\sim 3-500 \mathrm{mV} \mathrm{mm}{ }^{-2}$. It is present in both cytoplasmic environments and extracellular media. Therefore, endogenous ES plays an important role in several biological processes, namely tissue repair, wound healing, and embryogenesis. ${ }^{5,20,29-32}$ The application of exogenous ES in living cells is expected to influence their metabolic activities and thus, allow the development of functional therapeutic approaches.

The application of exogenous ES impacts cell processes such as migration, adhesion, proliferation, and differentiation (Fig. 4). ${ }^{5,20,22,23,33-35}$ The impact of the electrical cue on cell metabolic activities is still not completely clarified in terms of how cells interact with electrical signals. However, the literature attributes it to the cell membrane, the part responsible for most of its sensing capability towards electrical information. ${ }^{5}$

All cells are embedded in a complex electrolyte aqueous medium. Ion pumps control the dynamic equilibrium among the ions within and outside the cell membrane through transmembrane ion channels. The natural redistribution of these ions results in an electrical potential difference that regulates the cell membrane potential by activating or inhibiting its ion channels. ${ }^{5,35}$ Upon exogenous ES, the ionic equilibrium outside the cell membrane, and consequently inside of it, is perturbed, resulting in membrane permeability alteration, which ultimately triggers several cellular processes (e.g., cytoskeletal arrangement, protein distribution, electrotaxis, and $\mathrm{Ca}^{2+}$ flux). These ES-induced alterations are the potential mechanisms behind cellular responses such as proliferation, migration, differentiation, alignment, adhesion, and growth..$^{5,20,22,23,25,27}$

\section{Signal transduction pathway}

The major transduction pathway responsible for converting electrical information into biochemical cues is the activation of the mitogen-activated protein kinase (MAPK) cascades. These cascades regulate the messenger RNA (mRNA) transcriptions in response to exogenous ES. As a result, extracellular signal-regulated kinases (ERK 1/2 and ERK 5) and Jun aminoterminal kinases (JNK and p38MAPK) mediate several cell metabolic activities, including proliferation, differentiation, and apoptosis. ${ }^{20,22,36-38}$

\section{$\mathrm{Ca}^{2+}$ transients}

The calcium ion signalling pathway is one of the most critical factors that regulate cell activities, especially in the case of migration and differentiation. $\mathrm{Ca}^{2+}$ ions play a pivotal role in

\section{Electrical Stimulation at the Cellular level}
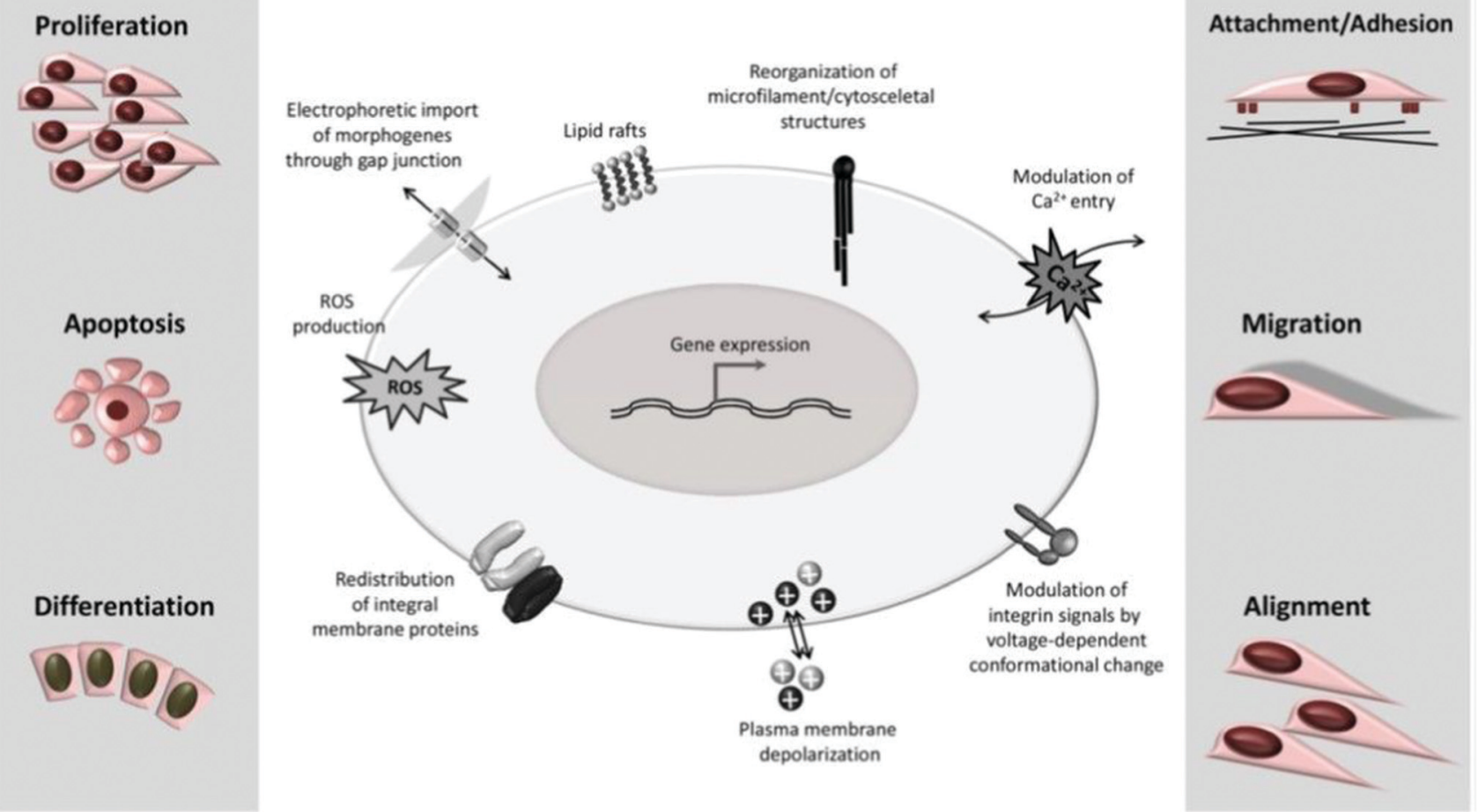

Fig. 4 Common cell metabolic activities influenced by exogenous ES. Reprinted from ref. 20, Copyright 2020 Springer. 
several vital activities of cells. Exogenous ES affects the membrane potential by altering the concentration of intracellular and extracellular ions such as $\mathrm{Na}^{+}, \mathrm{K}^{+}$, and $\mathrm{Ca}^{2+}$. As a result, oscillations in intracellular $\mathrm{Ca}^{2+}$ concentration occur via two main routes: higher calcium ion influx from the extracellular medium through ion channels or release of calcium ions from the endoplasmic reticulum (ER) internal stores. This intracellular increase in calcium ion concentration triggers the cytoskeletal calmodulin, resulting in more significant proliferation and a higher growth factor expression, such as vascular endothelial growth factor (VEGF) and transforming growth factor-beta 1 (TGF- $\beta 1$ ). Moreover, these alterations in the ion concentration inside and outside the cell lead to a difference in the cell membrane potential that alters its polarization and ultimately affects its migration under ES. ${ }^{5,22,27,39-45}$

\section{Cytoskeleton reorganization and actin distribution}

Cells, in the presence of an exogenous electrical field, can also respond by presenting a mechanical activity. This process is known as the reverse mechanotransduction effect. Upon an electrical field, cells undergo mechanical deformation (generating a mechanical tension) due to the reorganization and redistribution of the cytoskeletal protein filaments of actin. Moreover, the dipoles of actin become aligned along with the electrical field orientation polarization in response to ES. This ES-induced cytoskeletal structure rearrangement prompts cell electrotaxis/migration. ${ }^{20,22,40,46}$ The cell migration orientation is commonly observed towards the cathode; however, it depends on the studied cell line.

\section{Surface receptor redistribution}

Due to the high electrical resistivity of the cellular plasma membrane, electric-assisted cell processes occur in the outer environment of the cell rather than in its interior. The presence of applied ES can influence the redistribution of charged ligand-receptors (such as integrins) present in the cell membrane surface through electrophoresis. These electricalinduced spatial responses prompt the interaction of integrins (and also their linking proteins: actinin, talin, and vinculin) with actin microfilaments. Consequently, the integrin-actin interactions result in the formation of focal adhesion complexes, which ultimately influence the cell behavior in terms of adhesion and motility. ${ }^{20,22,47}$

\section{Adenosine triphosphate (ATP) synthesis}

Cell membrane ATPases possess the capability to absorb electrical energy (at a given frequency and magnitude) to induce and regulate the activity of membrane proteins. The presence of an electrical field orients the migration of protons (from the cytosol) by electrophoresis towards the mitochondrial membrane via $\mathrm{H}+$-ATPases proton pumps resulting in ATP generation. In general, this increase in ATP concentration enhances any cell activity that relies on energy consumption, such as regenerative processes..$^{20,22,48}$ Moreover, ATP level oscillations might induce cytoskeleton reorganization ${ }^{40}$ (following the previously described cytoskeleton redistribution mechanism), affecting cell attachment and migration.

\section{Heat shock proteins (HSPs)}

By definition, HSPs are proteins that cells produce when exposed to temperature stress (above their growth threshold) as a physiological stress response. It is hypothesized that the presence of an exogenous electrical input mimics this physiological stress acting as a stress inducer. Thus, it triggers a cellular response prompting the formation of stress proteins such as HSPs. These HSPs can interact with several transcription factors and extrinsic/intrinsic signalling pathways behind cell proliferation and differentiation. ${ }^{20,22,49}$

\section{Reactive oxygen species (ROS)}

Electrical field-induced ROS generation is considered another important factor that influences the metabolic activity of cells. ROS are naturally produced by nicotinamide adenine dinucleotide phosphate (NADPH) oxidase reactions. It is postulated that through ES, the membrane potential is affected (ion channels via electroporation), which influences the redox of NAPH that ultimately leads to ROS generation. ${ }^{50}$ It is commonly known that ROS leads to detrimental effects such as apoptosis, necrosis, DNA damage, and oxidation of proteins/lipids (oxidative stress). Nevertheless, moderate levels of intracellular ROS can induce cell differentiation and proliferation. ${ }^{20,22,51-53}$

\section{Lipid rafts}

It is generally accepted that the electrical field induces the polarization of cell membrane proteins and receptors that can regulate cell migration. Therefore, discrete glycolipid domains in the plasma membrane redistribute and congregate (originating lipid rafts) in response to the exogenous electrical field. Thus, lipid raft microdomains act as initial sensors towards electrical signals. Lipid rafts congregate in response to the electrical field, increasing in size and reducing their motility. Finally, lipid rafts polarize, which consequently induces intracellular activities that modulate cell migration. ${ }^{20,22,54,55}$

The briefly described cell mechanisms upon ES are interconnected in a complex cascade of events in cells and tissues. The success of exogenous ES on cells depends on several variables, including the chemical nature of the culture medium, experimental setup methodology of ES, and frequency, duration, and magnitude of the applied electrical stimulus. The latter is considered a crucial factor to modulate cell death upon ES. ${ }^{56}$

Considering cells seeded on a conductive scaffold (Fig. 3D), a general electrical stimulation dose threshold of $\leq 1 \mathrm{~V} \mathrm{~cm}^{-1}$ was reported. ${ }^{5,57}$ Conversely, the literature also reports greater vales of ES $\sim 500 \mathrm{~V} \mathrm{~cm}^{-1}$ to induce cell death if cells are seeded on non-conductive scaffolds. ${ }^{58}$ This indicates that the chemical nature of the polymer-based scaffold and its conductivity plays a significant role in establishing an electrical threshold. Moreover, another critical parameter to be considered when determining the successful outcome of ES on cells is the type of cell line. Each cell line presents some unique responses/behaviours 
and mechanisms under the applied electrical field, and detailed, thorough descriptions are beyond the scope of the present review.

\section{Common electro-responsive polymers utilized in the design of electro conductive scaffolds regarding ES-assisted cell engineering}

Conductive polymers can establish the required potential gradient by electrically stimulating cells and inducing several metabolic activities. Compared to non-conductive polymers, electro-responsive ones present some advantages, such as the development of ionic and/or electro-conductive scaffolds and the design of electro-responsive platforms with different sizes and shapes presenting intricate and complex geometries. Moreover, conductive scaffolds work as a bridge to ensure the communication between the precisely tuned exogenous electrical potential and cell lines. Thus, it properly delivers electrical signals to cells and provides a suitable environment to accommodate cells and support their metabolic activities promptly. ${ }^{1,5,59-62}$

Several electro-responsive polymers are used in the development of advanced conductive cell culture/tissue engineering scaffolds, including those from the conjugated polymer family poly(pyrrole) (PPy), ${ }^{63-65}$ polyaniline (PANI), ${ }^{66-70}$ poly(3,4ethylene dioxythiophene) (PEDOT)), ${ }^{71-74}$ and polysaccharides (chitosan (CS)), ${ }^{75-81}$ hyaluronic acid (HA), ${ }^{82}$ and alginate (ALG) ${ }^{83,84}$ Conductive scaffolds are also commonly obtained by combining highly conductive carbon-based materials (e.g., carbon nanotubes (CNTs), ${ }^{85-88}$ multiwalled carbon nanotubes (MWCNTs), ${ }^{78,89,90}$ graphene (GR), ${ }^{91-93}$ graphene oxide (GO) ${ }^{94}$ and reduced graphene oxide (rGO) $)^{95,96}$ with non-conductive polymers such as poly(lactic acid) (PLA), poly( $\varepsilon$-caprolactone) (PCL), poly(ethylene glycol) (PEG), collagen and its derivatives.

To investigate the possibility of employing electroresponsive polymers for developing conductive scaffolds for electro-assisted stimulation of cells, understanding the conducting mechanism of the constituent polymer is essential.

Conjugated polymers (CPs) are by far the most electroresponsive polymers commonly employed in the development of conductive scaffolds for tissue engineering applications (Fig. 5A). Conjugated polymers belong to the class of electroconductive polymers, and their conducting mechanism is intrinsically related to their organic backbone structure and doping process (Fig. 5B and Fig. 5C, respectively).

Briefly, conducting polymers (such as PPy, PEDOT, and PANI) present a unique chemical structure configuration consisting of alternating single $(\sigma)$ and double $(\pi)$ bonds. Unlike saturated single bonds, unsaturated double bonds also present weakly localized $\pi$-bonds. Their p-orbitals are overlapped with each other creating a more easily delocalized pathway. This pathway prompts electrons to flow alongside its backbone, allowing electro-conductivity. To enhance or endow electrical
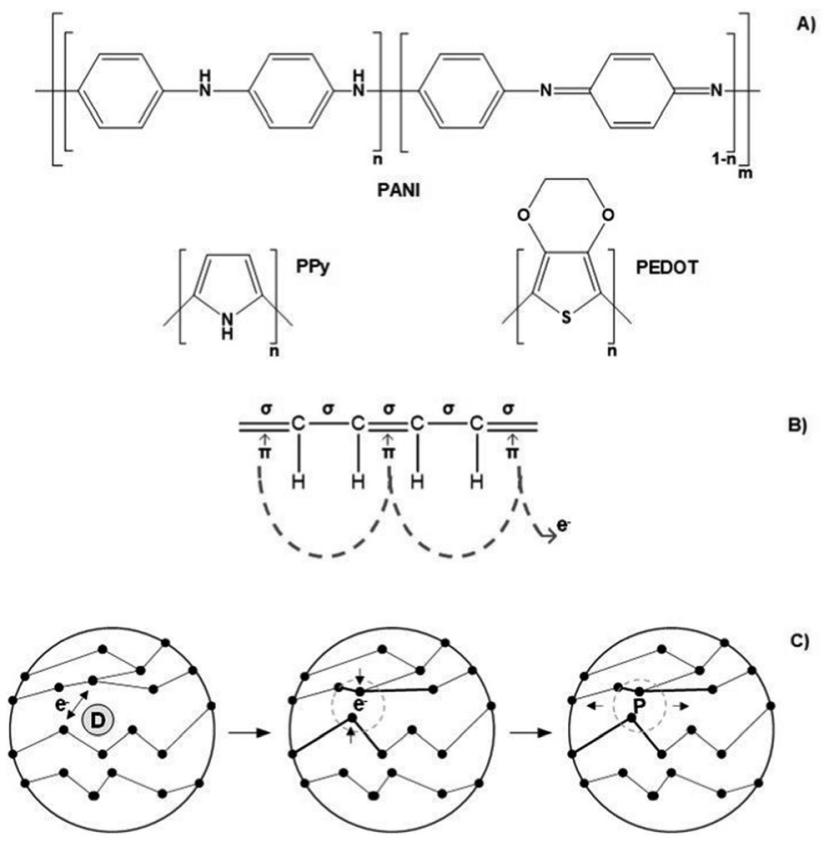

Fig. 5 Chemical structure of commonly utilized conjugated polymers for electro conducting scaffolds (A); illustration of its conducting mechanism on a conjugated backbone (B); scheme of the doping process (C).

conductivity, CPs undergo doping processes that involve adding (reduction) or removing (oxidizing) electrons to/from polymeric backbones through the utilization of dopants (e.g., hydrochloric acid or sulphonic acid). Oxidizing agents (p-dopants) remove electrons from the valence band (highest occupied orbital) and transfer them to the conduction band (lowest unoccupied orbital).

Conversely, reduction agents (n-dopants) add electrons to the conduction band where a radical anion is formed (polaron). A polaron consists of a loosely held electron surrounded by a crystal lattice distortion. Upon ES, the charge is carried in the form of these polarons that travels towards the working electrode, disrupting the stable conjugated backbone allowing the conduction of electrons. In general, the conductivity range of these classes of polymers is $10^{-2}-10^{5} \mathrm{~S} \mathrm{~cm}^{-1}$. However, several variables influence the conductivity amplitude, including the chemical nature of the CPs, polymer chain length, temperature, dopant concentration, and size and steric factors. ${ }^{5,97-99}$

Finally, these polymers are often combined with other materials (e.g., CS, collagen, PEG, and poly(vinyl alcohol) (PVA)) in order to compensate for their brittleness, low degree of swelling, and insolubility. ${ }^{7,99}$

Similarly, carbon-based materials such as GR, GO, rGO, CNTs, and MWCNTs (Fig. 6A and B) possess electroconductivity based on their chemical structural organization. Like CPs, carbon-based materials present alternating $\sigma-\pi$ bonds arranged in long sheets of hexagonal aromatic rings. Once again, this specific organization of single-double-single chemical bonds allows the formation of a "sea of delocalized electrons" (due to the overlap of p-orbitals from the $\pi$-bonds) that prompts the flow of electrons through this easily 


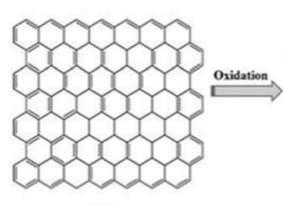

GR

GR

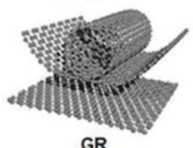

GR

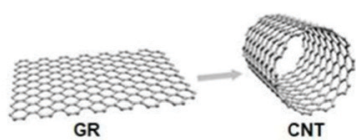

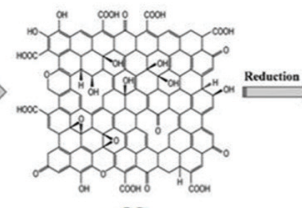

GO

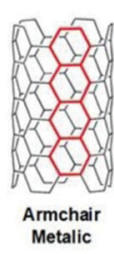

MWCNT
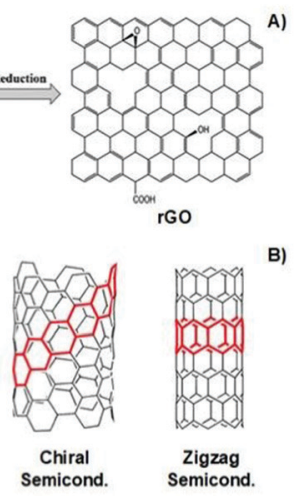

B)
Fig. 6 Structural illustration of graphene-based materials (A), carbon nanotubes and their atomic arrangement configuration (B). Reprinted from ref. 100, Copyright 2014; reprinted from ref. 101, Copyright 2019 John Wiley \& Sons Ltd, reprinted from ref. 102, Copyright 2016 Royal Society of Chemistry.

delocalized pathway, which, ultimately, results in a high electro-conductivity of up to $10^{7} \mathrm{~S} \mathrm{~m}^{-1}$. The unique atomic organization of the aromatic rings that comprise these materials directly influences their electrical properties.

The classic examples are armchair, zigzag, and chiral conformations (Fig. 6B). The armchair conformation presents the highest electrical conductivity due to its lower bandgap. ${ }^{24,100-103}$ Carbon-based materials are often utilized as filler agents to endow high conductivity to polymeric matrixes regarding tissue engineering applications.

Polyelectrolytes are a unique class of materials that present ionisable acidic and/or basic groups alongside their polymer backbone. Different from the electron-conducting materials presented earlier, polyelectrolytes belong to the class of ionconducing materials. Their conducting mechanism is based on the electrophoretic diffusion of their mobile counterion (an anion in the case of a polycation) in response to an applied electrical field (Fig. 7). ${ }^{104}$

These materials can be classified as single ion-conducting since the primary ion is chemically attached to the polymeric

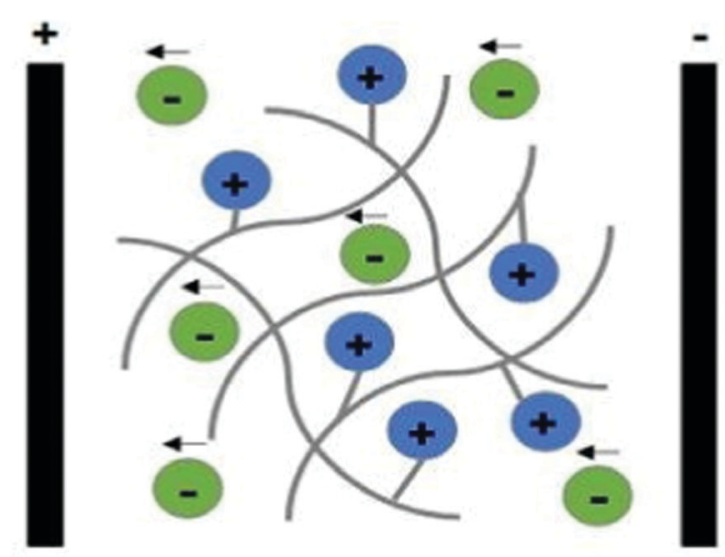

Fig. 7 Schematic representation of the ion conducting mechanism of polyelectrolytes (considering a polycation as an example). backbone, and its counterion is free to move. Upon ES, mobile counter ions diffuse towards oppositely charged electrodes (free anions electrophoretically diffuse towards the anode), acting as charge carriers, allowing the electric current to flow.

They are present in various configurations depending on the chemical nature of the polymer, namely polycations, polyanions, amphoteric polyelectrolytes, and polyzwitterions. Classic examples of polyelectrolytes include natural polymers (such as CS, alginate, and hyaluronic acid) and synthetic ones (poly(acrylic acid), Nafion ${ }^{\mathbb{B}}$, and Flemion ${ }^{\circledR}$ ).

Several variables can be used to tune the ionic conductivity of these materials, including the degree of crosslinking, chemical nature of the polyelectrolyte, the magnitude of the electrical field, temperature, swelling degree, size of counterions, and ionic strength of the aqueous environment. ${ }^{105-109}$ Polyelectrolytes are frequently used in the design of conducting scaffolds for cell culture due to their gel-forming capability and versatility.

\section{Current electro-responsive polymer-based scaffolds for ES-assisted cell engineering}

Several studies report the use of conductive polymer-based scaffolds for cell culture and tissue engineering applications without ES. These systems rely on the synergy between the endogenous ES of the cells and the conducting behaviour of the scaffold that could prompt cell metabolic activity. Nevertheless, these systems are not considered in the present review since they focus on electro-conductive platforms for electro-assisted cell culture.

Table 1 summarizes the main information from several exogenous ES-assisted cell stimulation studies throughout the literature (considering the last 5 years) of conductive platforms based on different polymeric materials. A more detailed description of each system is given in the next section of this work.

\subsection{Polypyrrole (PPy)}

PPy is one of the most explored conjugated polymers used in the design of conductive scaffolds for biomedical applications due to its high conductivity, and biocompatibility.

An interesting study performed by Song et al. evaluated the effect of scaffold geometry on human neural progenitor cell (hNPC) metabolism under electrical fields of 0 and $\sim 40 \mathrm{~V} \mathrm{~m}^{-1}$. In their study, 2D (thin films) and 3D (tubes) PPy-based conductive scaffolds were developed, and hNPC-alginate solutions were dispensed to each scaffold for further electro-assisted cell culture. hNPC-seeded scaffolds were electrically stimulated for $1 \mathrm{~h}$ and incubated for $24 \mathrm{~h}$ prior to quantitative gene expression analysis. The results demonstrated that (for a fixed scaffold geometry), several gene expression factors such as heparinbinding EGF like growth factor (HBEGF), heat shock protein family member 1 (HSPB1), glial cell-derived neurotrophic factor (GDNF), brain-derived neurotrophic factor (BDNF), neurotrophin 3 (NTF3) and enolase 2 (ENO2) were up to 33-fold higher 
Table 1 Summary of recent electro-responsive polymer-based platforms for electrostimulation of cells

\begin{tabular}{lll}
\hline Conductive material & Cell line & Electrical stimulus \\
\hline PPy $\sigma=57.8 \pm 4.2 \mathrm{~S} \mathrm{~m}^{-1}$ & hNPCs & 0 to $\sim 40 \mathrm{~V} \mathrm{~m}^{-1}$ for $1 \mathrm{~h}$ in vitro \\
& \\
& \\
PPy-coated cellulose $\sigma=$ & SH-SY5Y & $\begin{array}{l}100 \mathrm{mV} \mathrm{mm} \\
\sim 2.4 \times 10^{-5} \mathrm{~S} \mathrm{~cm}^{-1}\end{array}$ \\
& & in vitro $1 \mathrm{~Hz}$ pulses
\end{tabular}

Main findings

Ref.

$$
\sim 2.4 \times 10^{-5} \mathrm{~S} \mathrm{~cm}^{-1}
$$

PAN/PANI/Ni $\sigma=47.0 \pm$

$$
1.0 \mathrm{mS} \mathrm{cm}^{-1}
$$

SCs

$100 \mathrm{mV} \mathrm{cm}^{-1}$ for $1 \mathrm{~h}$ per day over 5 days in vitro

rBMSCs

$$
\begin{aligned}
& \text { PDA-functionalized PU/PANI } \\
& \sigma=\sim 9.0 \times 10^{-4} \mathrm{~S} \mathrm{~cm}^{-1}
\end{aligned}
$$

PEDOT- $c$-PDLLA CSC $=$

$417 \pm 62 \mu \mathrm{C} \mathrm{cm}-2$

PEDOT:PEG $\sigma=2.49 \times$

$10^{-3} \mathrm{~S} \mathrm{~cm}^{-1}$

C2C12

MG-63

PLA-CS doped with NPs

$\sigma=-$

CS/PPy-PLA/PCL

$\sigma=1.03 \mathrm{~S} \mathrm{~m}^{-1}$

HA-CNTs CSC $=\sim 35 \mathrm{mF} \mathrm{cm}^{-2}$

Lumbar dorsal

root ganglia

Collagen-GR $\sigma=3.93 \mathrm{mS} \mathrm{cm}^{-1}$

BM-MSCs

$1 \mathrm{~V}$ for 5 min in vitro

$2 \mathrm{~V}, 10 \mathrm{~ms}$ at $1 \mathrm{~Hz}$ for

$4 \mathrm{~h}$ per day over 7 days

in vitro

$100 \mathrm{mV}$ for $2 \mathrm{~h}$ per day over 5 days in vitro $\mathrm{AC}, 25 \mathrm{~Hz}, \pm 25 \mathrm{~ms}$ over 30 or $60 \mathrm{~min}$ in vitro
- Correlation between the scaffold's physical conformation and electrical stimulation on gene profile of hNPCS

- Significant changes in neurotrophic gene expressions under ES

- Physical conformation affects spatial electrical conductivity and nutrient availability cell adhesion and spread under ES
- Conductivity independent of fiber orientation of synthesized electrospun

- Longer and more branched neurites were observed upon ES onto conductive scaffolds

- Aligned surface morphology combined with

ES resulted in oriented neurite outgrowth

- Doping of Ni nanoparticles as an interesting approach to enhance electrical conductivity

- Higher electrical conductivity ensures proper electrostimulation of nerve cell growth

- More rapid ( $2.1 \times$ faster) SC proliferation upon ES.

- Higher amount of PDA led to an increase in

- Greater $(\sim 1.3 \times$ greater $)$ ALP expression upon ES

- The presence of exogenous ES enhanced (up to $2.4 \times$ greater) cell adhesion

- Higher cell proliferation was observed under ES

- Both morphological and electrical cues had a synergistic influence on cell activity

- Upon ES, higher ( $\sim 2 \times$ greater) gene expression was observed

- Hydrogel's chemical nature dependence on cell response upon ES

- Metallic NPs granted higher conductivities that prompted greater biomineralization upon ES

- Synergy between scaffold morphology and ES in cell growth and differentiation

- Neurite length and cell differentiation were slightly superior under ES

- Organized surface morphology and ES guided directional growth of neurites

- An electrical threshold of $200 \mathrm{mV} \mathrm{mm}^{-1}$ (for $30 \mathrm{~min}$ ) was suggested to significantly induce neurite outgrowth

- Longer neurites were observed under ES

- Conducting materials support cell growth and proliferation, and also an increase in gene expression under ES

- Exogenous ES led to an increase in several neuronal lineage markers during differentiation experiments

- Modular cell adhesion (upon ES) according to MWCNT content was observed

- Better cell layer arrangement and adhesion under ES.

- Cell viability dependent on rGO content under ES

- Higher cell adhesion observed upon exogenous ES
PCL-rGO $\sigma=6.8 \pm 0.36 \times$ $10^{-5} \mathrm{~S} \mathrm{~m}^{-1}$
hBM-SCs

$30 \mathrm{~V}$ for $3 \mathrm{~h}$ in vitro 

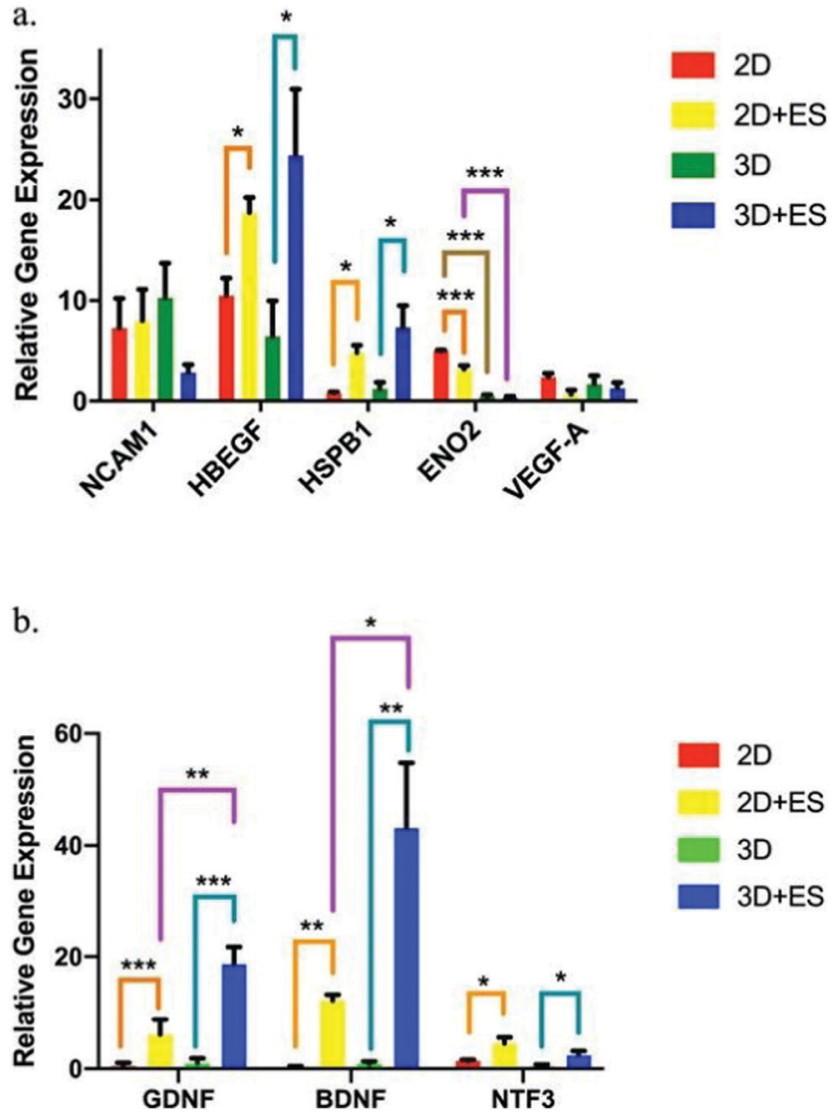

Fig. 8 hNPC gene expression factor fluctuations using 2D (thin films) and 3D (tubes) PPy-based scaffolds under ES (ANOVA * $p \leq 0.05,{ }^{* *} p \leq 0.01$ and $* * * p \leq 0.001$ ). (a) NCAM1, HBEGF, HSPB1, ENO2, and VEGF-A and (b) GDNF, BDNF, and NTF3. Reprinted from ref. 63, Copyright 2019 Nature.

under ES when compared to those results without the application of an electrical field (Fig. 8).

More interestingly, when comparing the results of gene expression values obtained for 2D and 3D scaffolds, it was observed that the scaffold shape presented an influence in determining the therapeutic potential of hNPCs. Under ES, 2D scaffolds enhanced the gene expression of ENO2 (Fig. 8a), whereas 3D scaffolds were more efficient in GDNF and BDNF neurotrophic factor expression (Fig. 8b). These gene expression factor variations are essential in several neurodegenerative diseases, namely Parkinson's, Alzheimer's, and Huntington's. ${ }^{110}$

Elashnikov conducted another interesting study regarding cellulose acetate butyrate (CAB)/PPy-based nanofiber scaffolds for the electrical stimulation of human neuroblastoma cells (SH-SY5Y) ${ }^{64}$ The focus was to observe the synergy interplay between the scaffold's physical cues and electrical signals on neuronal cell behaviour.

The results demonstrated that the surface topography of conductive scaffolds, as well as electrical signals $\left(100 \mathrm{mV} \mathrm{mm}^{-1}\right.$ at $1 \mathrm{~Hz}$ pulses for $1 \mathrm{~h}$ ), presented a direct influence on cell growth, orientation, and alignment. Compared to control (TCP), the presence of conductive PPy on the scaffold induced significant changes in the morphology of SH-SY5Y cells, for both stimulated and non-stimulated samples.
Additionally, the surface topography of conductive scaffolds prompted oriented cell growth when comparing aligned and uniaxial aligned platforms.

The effect of electrical stimulation on cell metabolic activity was also observed for electro-conducting $\mathrm{CAB} / \mathrm{PPy}$-based scaffolds. In general, applying an electrical stimulus on SH-SY5Y cells increased the average neurite length and branching points. The cell viability assay was also performed to address the effect of ES upon cell metabolic activity.

The results demonstrated a linear relationship between long periods of ES time (up to 7 days) and a decrease in the cell metabolic activity (inhibited proliferation). The authors suggest that this reduction in SH-SY5Y proliferation is because these cells undergo differentiation after electrical stimulation. ${ }^{64}$

\subsection{Polyaniline (PANI)}

PANI is another classical CP widely utilized in developing conductive scaffolds due to its excellent conductivity, chemical stability, and processability. Polyacrylonitrile(PAN)/PANI electrospun nanofibers doped with Ni nanoparticles were synthesized to investigate the effect of scaffold impedance on Schwann cell (SC) metabolism after electrical stimulation. ${ }^{70}$

The results demonstrated that the electro-conductivity of the scaffolds was enhanced by the presence of PANI (compared to control) and significantly higher $(\sim 6.5 \times$ higher $)$ when further doped with Ni nanoparticles, as expected. To evaluate the interplay between the scaffold's conductivity and SC fate under ES, a proliferation experiment was performed (Fig. 9). The results suggest that similar optical density (OD) values were observed for samples without ES, regardless of the intrinsic conductivity.

Conversely, ES samples doped with Ni nanoparticles (and thus those with higher electro-conductivity) presented the highest (4.7× greater) cell proliferation when compared to those samples measured without ES. Moreover, SEM micrographs revealed higher cell attachment onto scaffolds with higher electro-conductivity (PAN/ $\mathrm{PANI} / \mathrm{Ni}$ ) when electro stimulated, which corroborates with previously reported cell proliferation results. ${ }^{70}$

Another interesting study regarding electro-responsive PANI-based scaffolds was conducted by Ghorbani $e t$ al. In this study, the influence of the chemical composition of prepared

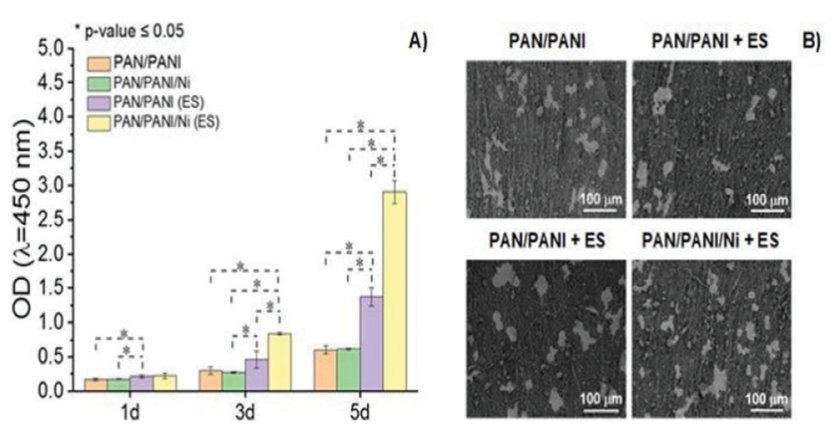

Fig. 9 Proliferation behaviour (A) and SEM images (B) of SCs as a function of the chemical nature of conductive scaffolds and presence of $E S$ (100 mV cm ${ }^{-1}$ for $1 \mathrm{~h}$ per day over 5 days) (ANOVA * significant difference $p<0.05)$. Reprinted from ref. 70, Copyright 2021 Elsevier. 
electrospun polyurethane (PU)/PANI scaffolds, modified with bioactive polydopamine (PDA), on metabolic responses of rat bone marrow mesenchymal stem cells (rBMSCs) in the presence/absence of ES was determined. ${ }^{67}$

Different electrospun formulations were prepared, including PU/PANI + PDA and PU/PANI/PVA + PDA. The presence of PVA in the chemical composition of electrospun scaffolds significantly influenced several physicochemical, electronic, and mechanical properties. Therefore, lower water contact angles ( $\sim 2 \times$ inferior), higher Young's modulus $(\sim 1.3 \times$ greater $)$, and lower conductivity $(\sim 1.3 \times$ lower $)$ were observed for PU/PANI/ PVA + PDA samples when compared to PU/PANI + PDA. Moreover, higher osseointegration was observed for PU/PANI/PVA + PDA scaffolds immersed in simulated body fluid (SBF) due to the higher hydrophilic character of PVA that prompted the ionic interactions of SBF ions with the scaffold, which ultimately promoted hydroxyapatite formation.

The effect of ES $\left( \pm 500 \mathrm{mV} \mathrm{cm}{ }^{-1}\right.$ for $1 \mathrm{~h}$ per day $)$ was evaluated on rBMSC adhesion and viability. In general, the applied electrical field enhanced cell spreading and filopodia formation onto conductive PANI-based scaffolds. Finally, the influence of exogenous electrical fields on cell differentiation capability (osseoblast generation) was addressed and evaluated in terms of alkaline phosphatase (ALP) expression. The results demonstrated that a higher concentration of ALP expression (up to $\sim 1.3 \times$ greater) under ES was observed for 14 days. The developed electro-conductive PANI-based scaffolds could be considered promising platforms for bone repair applications. ${ }^{67}$

\subsection{Poly(3,4-ethylene dioxythiophene) (PEDOT)}

The poly(thiophene) derivative, PEDOT, is another classic example of a conducting polymer commonly employed in the development of conductive scaffolds for tissue engineering applications. PEDOT presents high conductivity, biocompatibility, and hydrophobicity similar to other electron-conducting polymers from the CP family. Combining PEDOT with more biodegradable and hydrophilic polymers is a strategy used to overcome its low intrinsic biodegradability. Copolymers of PEDTO-co-poly(DL-lactide) (PDLLA) films were synthesized.

The developed scaffolds worked as conducting platforms for fibroblast cell culture, focusing on exploring the effect of ES in cell adhesion and proliferation processes. ${ }^{72}$ Proliferation studies of NIH-3T3 cells seeded on conductive scaffolds showed a significant influence of the applied exogenous electrical field (Fig. 10A). An increase in fibroblast proliferation was observed for electro-stimulated conductive PEDOT-based samples, which prompted better development of NIH-3T3 cells for 11 days. Therefore, SEM micrographs also revealed that in the presence of electrical potential, higher cell adhesion and growth were obtained when compared to samples without ES (Fig. 10B). ${ }^{72}$

The presence of conducting PEDOT on PEG-based hydrogels was demonstrated to enhance the differentiation of $\mathrm{C} 2 \mathrm{C} 12$ myoblasts into myotubes. ${ }^{71}$ The results demonstrated an interesting interplay between scaffold surface pattern and conductivity in myoblast differentiation and migration (Fig. 11). The myotubes' spatial configuration was different according to the
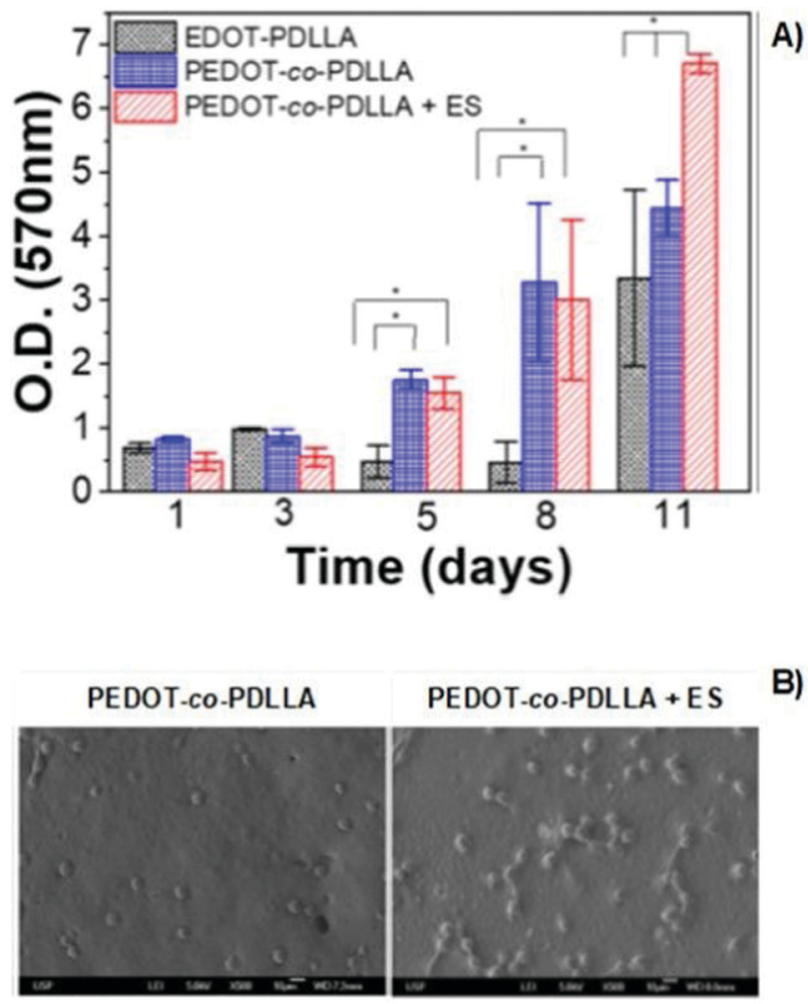

Fig. 10 MTT assay of PEDOT-based films (A) and SEM micrographs (B) of $\mathrm{NIH}$-3T3 fibroblasts in the presence or absence of electrical potential of $1 \mathrm{mV}$ (ANOVA * significant difference $p<0.05$ ). Reprinted from ref. 72 , Copyright 2020 American Vacuum Society.

surface of each hydrogel (either flat (F) or patterned (P)). For example, thicker and shorter myotubes were observed in hydrogels presenting a flat surface compared to patterned ones. Moreover, concerning the influence of ES, myotubes were more connected to each other and highly oriented when compared to the same samples where no ES was applied. PEG-PEDOT hydrogels reveal the importance of conjugating surface properties (anisotropic architecture) with electro-conductivity resulting in the design of advanced scaffolds with promising tissue engineering applications. ${ }^{71}$

\subsection{Chitosan (CS)}

The deacetylate form of chitin, also known as chitosan (CS), is a natural polymer found in exoskeletons of arthropods and cell walls in fungi. It is a polycationic polysaccharide broadly explored for a diverse array of biomedical applications due to its intrinsic properties, namely biodegradability, biocompatibility, availability, bioadhesion, antimicrobial activity, $\mathrm{pH}-$ responsive capacity, processing versatility, and gel-forming capability. ${ }^{111,112}$ Taking advantage of the array of CS properties, this polysaccharide is often combined with conductive materials to obtain advanced biocompatible/biodegradable and conducting scaffolds for ES-assisted tissue engineering. PLA-CS hydrogels loaded with different nanoparticles (such as titanium dioxide $\left(\mathrm{TiO}_{2}\right)$, gold $(\mathrm{Au})$, and platinum $\left.(\mathrm{Pt})\right)$ were developed. ${ }^{77}$ 


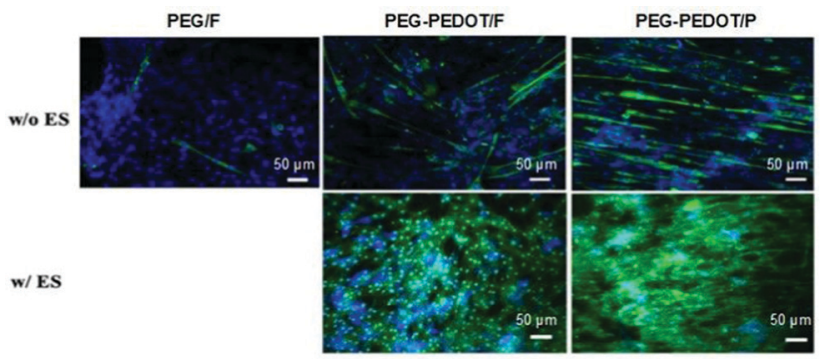

Fig. 11 Influence of the physicochemical nature of hydrogels on myotube formation with (w/) and without (w/o) ES. Immunostaining images reveal the expression of myosin heavy chain (green) and nuclei (blue) on day 7 of culture. Reprinted from ref. 71, Copyright 2019 American Chemical Society.

The effect of direct current ES (of 5V) was directly assessed by biomineralisation experiments with human osteosarcoma cell line (MG-63) in SBF medium. The results demonstrated that a difference in the DC-induced biomineralisation percentage was observed according to the type of metallic nanoparticles present in each hydrogel. Au-loaded samples present the highest (up to $1.25 \times$ higher) biomineralisation percentage compared to Pt-/ $\mathrm{TiO}_{2}$-loaded samples and control (PLA-CS hydrogels without nanoparticle loading). This result is attributed to the highest electro-conductivity of gold nanoparticles that provoked the ionic interactions between the scaffold and the electrolytes (e.g., calcium and phosphorous) present in the SBF medium. ${ }^{77}$

Another interesting study regarding chitosan-based conductive platforms has been recently performed for nerve repair and regeneration applications. Therefore, CS/PPy-PLA/PCL fibre films were prepared for ES of PC12 cells. ${ }^{65}$ The study was focused on the influence of electrical cues, and the presence of chitosan on cell metabolic activities such as differentiation, neurite growth, and adhesion. In general, the results demonstrated a synergetic interplay between the chemical nature of chitosan and the electrical signals. For instance, the neurite growth and cell differentiation rate (Fig. 12A and B, respectively) were greater (at least $3 \times$ greater) for samples containing CS without applying an electrical stimulus. Moreover, the application of $\mathrm{ES}(100 \mathrm{mV}, 2 \mathrm{~h}$ per day for 5 days) led to a discrete increase in the neurite length and cell differentiation ratio with the cultivation time.

Concomitantly, immunofluorescence micrographs revealed that the presence of chitosan induced higher cell outgrowth. This experiment also demonstrated that upon ES, longer neurites were observed for samples containing CS compared to those without CS in its formulation (Fig. 12C). Finally, the impact of electrical cues on PC12 attachment onto CS-based films was evaluated (Fig. 12D).

The results demonstrated that neurites attached to the surface of samples and growth cones were more elongated, presenting more filopodia around them. ${ }^{65}$ Moreover, the fibrepatterned surfaces of the prepared films were able to guide and orient neurite growth along the fibre axis.
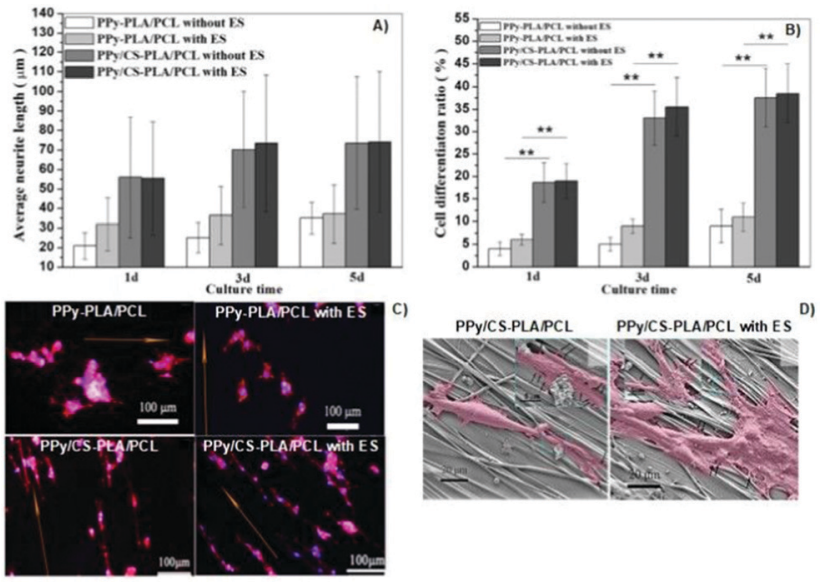

Fig. 12 Effect of the chemical nature of the prepared films and also of the electrical cues on neurite length $(A)$ and cell differentiation ratios (B); immunofluorescence (phalloidin/DAPI) micrographs of cells seeded on synthesized samples (orange arrows indicate the direction of fibre axis) (C); SEM micrographs of PC12 cells attached to the surface of CS-based samples with and without ES (cells are marked in pink and filopodia sites are highlighted by black arrows) (D). Reprinted from ref. 65, Copyright 2019 John Wiley \& Sons Ltd.

\subsection{Other polymers conjugated with carbon-based materials}

Carbon-based materials such as CNTs, MWCNTs, GR, GO, and rGO are widely utilized as fillers to induce or promote high electro-conductivity in several platforms regarding tissue engineering applications. ${ }^{103}$

A recent work developed conductive platforms based on HACNTs nanofillers. ${ }^{82}$ The influence of exogenous ES magnitude (AC of 150, 200, and $250 \mathrm{mV} \mathrm{mm}^{-1}, 25 \mathrm{~Hz}$ biphasic square waves, \pm 25 ms pulse width and $\pm 50 \%$ duty cycle) on lumbar dorsal root ganglia cell metabolism was evaluated. In general, the results demonstrated that upon ES, longer neurite outgrowth was observed compared to samples without electrical stimulus. More interestingly, the results suggest an electrical field threshold of $200 \mathrm{mV} \mathrm{mm}{ }^{-1}$ for 30 min to obtain significantly longer neurites. Another important observation is the ES application time regime. Independent of the chemical nature of the synthesized scaffold, the neurite length was similar at either 200 or $250 \mathrm{mV} \mathrm{mm}^{-1}$ applied for $30 \mathrm{~min}$. Nevertheless, for $60 \mathrm{~min}$ of ES at $200 \mathrm{mV} \mathrm{mm}^{-1}$, higher neurite growth was observed for HA-CNT scaffolds when compared to HA or unstimulated samples. ${ }^{82}$

Conductive collagen-graphene cryogels with potential tissue engineering applications were also developed. ${ }^{92}$ The effect of the electrical stimulus on rat bone marrow-derived mesenchymal stem cells (BM-MSCs) and their differentiation into neuronal-like cells was demonstrated. Herein, amine- functionalized graphene was utilized as a crosslinker agent and as a filler to promote electro-conductivity in the designed cryogels. Electrical cues of $1 \mathrm{~V}$ for $5 \mathrm{~min}$ were utilized to promote electrostimulation of cells previously seeded on scaffolds. The authors have discovered that different gene expressions (CD73 and CD90) could be obtained according to the chemical nature of the scaffolds under ES. 

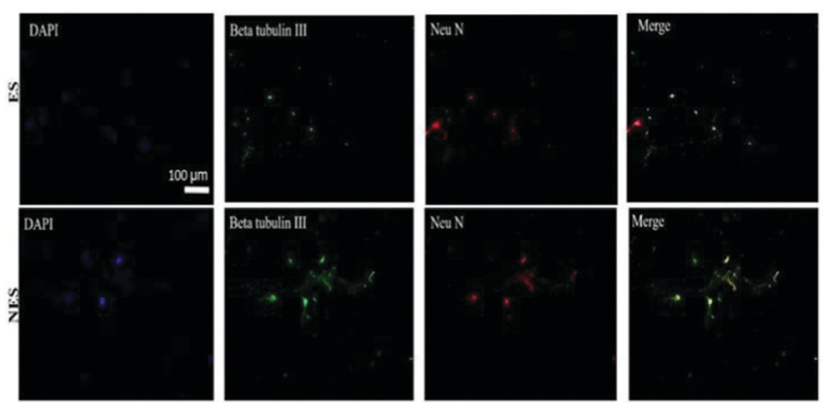

Fig. 13 Immunochemistry images of BM-MSC differentiation behaviour on conducting scaffolds in the presence and absence of an electrical field. Codes are denoted as: electrically stimulated (ES), non-electrically stimulated (NES) and (4',6-diamidino-2-phenylindole) (DAPI) blue-fluorescent DNA stain. Reprinted from ref. 92, Copyright 2021 Elsevier.

Moreover, these gene expression fluctuations were also timedependent. For instance, a decrease in CD73 gene expression was observed as the graphene content of scaffolds increased for up to 3 days of measurements under ES.

Conversely, the increase in graphene content and the presence of an electrical field significantly augmented the CD73 gene expression levels at day 5. In the case of CD90 gene expressions, the increase in graphene content led to a decrease in CD90 levels after day 5 of ES.

Additionally, an inverse relationship was observed between the CD90 gene expression and the graphene content without ES. The differentiation capability of BM-MSCs under the influence of electrical fields was studied in vitro for cells seeded on conducting scaffolds. The immunocytochemistry results (Fig. 13) reveal that conducting scaffolds could promote cell differentiation in the presence and absence of ES. In the presence of ES, expressions of mature (Neu N) and immature neuron marker ( $\beta$-tubulin III) were observed for BM-MSCs cultured on scaffolds. This result suggests that the developed scaffolds are promissing platforms to potentially induce cell differentiation upon ES. ${ }^{92}$

Agarose hydrogels filled with MWCNTs were developed to evaluate the influence of ES on the Schwann cell line (RSC96). ${ }^{89}$ An electrical stimulus of 3-4 $\mathrm{V}$ for $30 \mathrm{~min}$ per day at a frequency of $10 \mathrm{~Hz}$ was applied to induce RSC96 cell growth onto the scaffolds. The results demonstrated highly conductive scaffolds (conductivity up to $\sigma=\sim 1.5 \mathrm{~S} \mathrm{~m}^{-1}$ ) and supported cell growth without ES. Nevertheless, a higher cell arrangement was attained along the longitudinal axis of scaffolds upon applying electrical signals.

Additionally, the presence of an electric field-induced higher cell adhesion on hydrogels with 0.025 and 0.05 wt $\%$ MWCNTs is observed compared to control ( $0 \%$ MWCNTs) and $0.1 \%$ MWCNTs scaffolds. ${ }^{90}$

Another attractive conducting scaffold was obtained by combining PCL with rGO particles. ${ }^{95}$ The metabolic activity of human bone marrow-derived mesenchymal stem cells (hBMSCs) on 3D-printed scaffolds in the presence of electrical cues (30 $\mathrm{V}$ for $3 \mathrm{~h}$ ) was evaluated. Briefly, the presence of rGO (10 wt\%) particles in the 3D-printed scaffold increased the cell-scaffold interactions by reducing its hydrophobicity and, thus, prompted cell adhesion and increased cytocompatibility. Moreover, the presence of electrical cues led to an increase in cell adhesion (at least $1.5 \times$ higher) for all samples (independent of the presence of rGO particles). ${ }^{95}$

\section{Conclusions}

The electrical stimulation of cells can induce several metabolic pathways, namely modulation of $\mathrm{Ca}^{2+}$ concentration, cell membrane polarization, spatial redistribution of membrane proteins, reorganization of actin microfilaments/cytoskeletal structures, and alteration of the conformation of integrins. These alterations lead to different cell metabolic activities such as proliferation, differentiation, adhesion, alignment, migration, and apoptosis.

Different methodology strategies were employed to develop conductive scaffolds for ES-assisted cell culture/tissue engineering, namely electrospinning, lyophilization, solvent casting, AM-related methodologies, and micropatterning. The former is the most commonly employed approach to designing conductive scaffolds with oriented surface patterns.

Several polymers were utilized in the design of advanced conductive scaffolds with tuned response upon ES, including conjugated polymers (PEDOT, PPy or PANI), natural polymers (CS and collagen), and carbon-based materials (e.g. CNTs, MWCNTs, GO, and rGO) combined with PEG, PCL, and PLA matrixes. Most of these systems are composed of two or more of these materials in attempting to obtain high conductivitybiocompatibility/low cytotoxicity-biodegradability synergy.

The physicochemical and electrical properties of the scaffolds play a significant role in determining cell fate. Moreover, cell metabolic activities triggered by ES cues are described by several complex mechanisms which are not fully understood. Obtaining advanced engineered scaffolds that present precise and finely reproducible results regarding cell culture systems are still a considerable challenge. With this in mind, the lack of information in the literature regarding the washing procedure of designed scaffolds is an important factor that must be considered. Residual components present in the produced scaffold can affect its physicochemical, mechanical, and electrical properties, impacting cell metabolism and, thus, cell fate.

Another key factor that is often disregarded is the biodegradability of the polymer-based conducting platforms. To the best of our knowledge, the majority of the studies developed so far are more focused on providing "proofs of concepts" with respect to ESassisted cell culture and biocompatibility rather than its biodegradability. Indeed, there is a clear effort to utilize polymers that are potential candidates to induce biodegradability (such as chitosan, cellulose, alginate, collagen, PLA and PEG) by enzymatic and/or hydrolytic pathways. Nevertheless, few data are currently presented and should be addressed in the following studies regarding conducting platforms for ES-assisted cell culture.

Efforts are currently being made to develop conducting scaffolds that can precisely control/regulate cell metabolism 
under ES. Furthermore, the synergy between the physicochemical and mechanical properties of the scaffolds and cell metabolism is explored. Nevertheless, due to the complexity of each cell line and its specificities, the application of these advanced conducting scaffolds in complex environments (e.g., in vivo) is an important subject that requires more clarification and data.

The obtainment of highly engineered scaffolds that simultaneously present several properties including biocompatibility, antifouling, and antibacterial capacity, presence of interconnected porous cavities, and electro-responsiveness capable of being transversal to different cell lines is the huge challenge to be addressed in future investigations. Moreover, thoroughly evaluating the performance of in vitro ES-cultured tissues and in vivo systems could also be an important step in shaping and guiding further scaffold technologies for electro-assisted cell culture engineering.

\section{Abbeviations}

\begin{tabular}{|c|c|}
\hline ALG & Alginate \\
\hline ALP & Alkaline phosphatase \\
\hline $\mathrm{AM}$ & Additive manufacturing \\
\hline ATP & Adenosine triphosphate \\
\hline BDNF & Brain-derived neurotrophic factor \\
\hline $\mathrm{CA}$ & Contact area \\
\hline $\mathrm{CAB}$ & Cellulose acetate butyrate \\
\hline CNTs & Carbon nanotubes \\
\hline CPs & Conjugated polymers \\
\hline CS & Chitosan \\
\hline $\mathrm{E}$ & Elastic (Young) moduli \\
\hline ECM & Extracellular matrix \\
\hline EGF & Endothelial growth factor \\
\hline EMS & Electromagnetic stimulation \\
\hline ENO2 & Enolase 2 \\
\hline ER & Endoplasmic reticulum \\
\hline ERK & Extracellular signal-regulated kinases \\
\hline ES & Electrical stimulation \\
\hline FFF & Fused filament fabrication \\
\hline GDNF & Glial cell-derived neurotrophic factor \\
\hline GO & Graphene oxide \\
\hline GR & Graphene \\
\hline HA & Hyaluronic acid \\
\hline HBEGF & Heparin-binding EGF \\
\hline hNPCs & Human neural progenitor cells \\
\hline HSPB1 & Heat shock protein family member 1 \\
\hline HSPs & Heat shock proteins \\
\hline JNK & Jun amino-terminal kinases \\
\hline MAPK & Mitogen-activated protein kinase \\
\hline mRNA & Messenger RNA \\
\hline MWCNTs & Multiwalled carbon nanotubes \\
\hline NADPH & Nicotinamide adenine dinucleotide phosphate \\
\hline NTF3 & Neurotrophin 3 \\
\hline OD & Optical density \\
\hline PAN & Polyacrylonitrile \\
\hline PANI & Polyaniline \\
\hline
\end{tabular}

$\begin{array}{ll}\text { PCL } & \text { Poly(e-caprolactone) } \\ \text { PDA } & \text { Polydopamine } \\ \text { PDLLA } & \text { PEDTO-co-poly(DL-lactide) } \\ \text { PEDOT } & \text { Poly(3,4-ethylene dioxythiophene) } \\ \text { PEG } & \text { Poly(ethylene glycol) } \\ \text { PLA } & \text { Poly(lactic acid) } \\ \text { PPy } & \text { Polypyrrole } \\ \text { PU } & \text { Polyurethane } \\ \text { PVA } & \text { Poly(vinyl alcohol) } \\ \text { R } & \text { Surface roughness } \\ \text { rBMSCs } & \text { Rat bone marrow mesenchymal stem cells } \\ \text { rGO } & \text { Reduced graphene oxide } \\ \text { ROS } & \text { Reactive oxygen species } \\ \text { SBF } & \text { Simulated body fluid } \\ \text { SCs } & \text { Schwann cells } \\ \text { SH-SY5Y } & \text { Human neuroblastoma cells } \\ \text { TGF- } \beta 1 & \text { Transforming growth factor-beta 1 } \\ \text { VEGF } & \text { Vascular endothelial growth factor } \\ \text { WCA } & \text { Water contact angle }\end{array}$

\section{Author contributions}

Conceptualization: Akel F. Kanaan and Ana P. Piedade. Writing-original draft preparation: Akel F. Kanaan. Writingreview and editing: Akel F. Kanaan and Ana P. Piedade. Project administration and funding acquisition: Ana P. Piedade. All authors have read and agreed to the published version of the manuscript.

\section{Conflicts of interest}

There are no conflicts to declare.

\section{Acknowledgements}

This research was partially supported by FEDER funds through the programs COMPETE 2020 - Programa Operacional Fatores de Competitividade - Portugal 2020 and by national funds through FCT - Fundacão para a Ciência e a Tecnologia, I.P. under the projects POCI-01-0145-FEDER-030767, POCI-01-0247FEDER-024533 and UIDB/00285/2020.

\section{References}

1 H. Palza, P. A. Zapata and C. Angulo-Pineda, Materials, 2019, $12,277$.

2 C. Ning, Z. Zhou, G. Tan, Y. Zhu and C. Mao, Prog. Polym. Sci., 2018, 81, 144-162.

3 R. Dong, P. X. Ma and B. Guo, Biomaterials, 2020, 229, 119584.

4 F. Xing, L. Li, C. Zhou, C. Long, L. Wu, H. Lei, Q. Kong, Y. Fan, Z. Xiang and X. Zhang, Stem Cells Int., 2019, 2180925. 
5 Z. Zhang, M. Rouabhia and S. E. Moulton, Conductive Polymers, CRC Press, Taylor \& Francis Group, Boca Raton, FL, 1st edn, 2018.

6 T. Lu, Y. Li and T. Chen, Int. J. Nanomed., 2013, 8, 337-350.

7 N. Alegret, A. Dominguez-Alfaro and D. Mecerreyes, Biomacromolecules, 2019, 20, 73-89.

8 A. Keirouz, M. Chung, J. Kwon, G. Fortunato and N. Radacsi, Wiley Interdiscip. Rev.: Nanomed. Nanobiotechnol., 2020, 12, 1-32.

9 T. Peijs, in Comprehensive Composite Materials II, ed. P. W. R. Beaumont and C. H. Zweben, Elsevier Inc., Amsterdam, Netherlands, 2018, vol. 6, pp. 162-200.

10 Y. Long, X. Yan, X. Wang, J. Zhang and M. Yu, in Electrospinning: Nanofabrication and Applications, ed. B. Ding, $\mathrm{X}$. Wang and J. Yu, Elsevier Inc., Amsterdam, Netherlands, 2019, pp. 21-52.

11 R. Asmatulu and W. S. Khan, Synthesis and applications of electrospun nanofibers, Elsevier Inc., Amsterdam, Netherlands, 2019, pp. 17-39.

12 S. K. Sinha, in 3D and 4D Printing of Polymer Nanocomposite Materials, ed. E. Hayes, Elsevier Inc., Amsterdam, Netherlands, 2020, pp. 119-160.

13 A. F. Kanaan, A. C. Pinho and A. P. Piedade, Polymers, 2021, 13, 2713.

14 M. Ebrahimi, Front. Mater. Sci., 2021, 15, 352-373.

15 N. Muzzio, S. Moya and G. Romero, Pharmaceutics, 2021, 13, 792.

16 X. Chen, H. Fan, X. Deng, L. Wu, T. Yi, L. Gu, C. Zhou, Y. Fan and X. Zhang, Nanomaterials, 2018, 8, 1-15.

17 C. F. Guimarães, L. Gasperini, A. P. Marques and R. L. Reis, Nat. Rev. Mater., 2020, 5, 351-370.

18 B. Majhy, P. Priyadarshini and A. K. Sen, RSC Adv., 2021, 11, 15467-15476.

19 M. Ferrari, F. Cirisano and M. Carmen Morán, Colloids Interfaces, 2019, 3, 48.

20 L. Leppik, K. M. C. Oliveira, M. B. Bhavsar and J. H. Barker, Eur. J. Trauma Emerg. Surg., 2020, 46, 231-244.

21 Y. Wang, M. Rouabhia and Z. Zhang, Biochim. Biophys. Acta, Gen. Subj., 2016, 1860, 1551-1559.

22 G. Thrivikraman, S. K. Boda and B. Basu, Biomaterials, 2018, 23(150), 60-86.

23 C. Chen, X. Bai, Y. Ding and I. S. Lee, Biomater. Res., 2019, 23, 1-12.

24 L. P. da Silva, S. C. Kundu, R. L. Reis and V. M. Correlo, Trends Biotechnol., 2020, 38, 24-49.

25 R. Zhu, Z. Sun, C. Li, S. Ramakrishna, K. Chiu and L. He, Exp. Neurol., 2019, 319, 112963.

26 H. Cheng, Y. Huang, H. Yue and Y. Fan, Stem Cells Int., 2021, 6697574.

27 R. Balint, N. J. Cassidy and S. H. Cartmell, Tissue Eng., Part $B, 2013,19,48-57$.

28 M. Saqib, N. S. Francis and N. J. Francis, Int. Youth Conf. Radio Electron. Electr. Power Eng., 2020, 2020, 1-5.

29 M. Levin, Mol. Biol. Cell, 2014, 25, 3835-3850.

30 A. Jahanshahi, L. M. Schönfeld, E. Lemmens, S. Hendrix and Y. Temel, Mol. Neurobiol., 2014, 49, 1005-1016.
31 E. Serena, E. Figallo, N. Tandon, C. Cannizzaro, S. Gerecht, N. Elvassore and G. Vunjak-Novakovic, Exp. Cell Res., 2009, 315, 3611-3619.

32 R. H. W. Funk, Front. Physiol., 2015, 6, 1-8.

33 S. Zhao, A. S. Mehta and M. Zhao, Cell. Mol. Life Sci., 2020, 77, 2681-2699.

34 M. R. Love, S. Palee, S. C. Chattipakorn and N. Chattipakorn, J. Cell. Physiol., 2018, 233, 1860-1876.

35 B. Cortese, I. E. Palamà, S. D'Amone and G. Gigli, Integr. Biol., 2014, 6, 817-830.

36 Y. D. Shaul and R. Seger, Biochim. Biophys. Acta, Mol. Cell Res., 2007, 1773, 1213-1226.

37 Y. Sun, W.-Z. Liu, T. Liu, X. Feng, N. Yang and H.-F. Zhou, J. Recept. Signal Transduction, 2015, 35, 600-604.

38 H. Rubinfeld and R. Seger, in MAP Kinase Signaling Protocols, ed. R. Seger, Humana Press, Totowa, NJ, 2004, pp. 1-28.

39 H. Zhuang, W. Wang, R. M. Seldes, A. D. Tahernia, H. Fan and C. T. Brighton, Biochem. Biophys. Res. Commun., 1997, 237, 225-229.

40 I. Titushkin and M. Cho, Biophys. J., 2009, 96, 717-728.

41 J. F. Perez-Zoghbi, C. Karner, S. Ito, M. Shepherd, Y. Alrashda and M. J. Sanderson, Pulm. Pharmacol. Ther., 2009, 22, 388-397.

42 F. M. P. Tonelli, A. K. Santos, D. A. Gomes, S. L. da Silva, K. N. Gomes, L. O. Ladeira and R. R. Resende, in Calcium Signaling, ed. M. S. Islam, Springer, Dordrecht, Netherlands, 2012, pp. 891-916.

43 R. E. Dolmetsch, K. Xu and R. S. Lewis, Nature, 1998, 392, 933-936.

44 T. Nakano, M. J. Moore, F. Wei, A. V. Vasilakos and J. Shuai, IEEE Trans Nanobioscience, 2012, 11, 135-148.

45 R. J. McMurray, M. J. Dalby and P. M. Tsimbouri, J. Tissue Eng. Regener. Med., 2015, 9, 528-539.

46 J. T. Parsons, A. R. Horwitz and M. A. Schwartz, Nat. Rev. Mol. Cell Biol., 2010, 11, 633-643.

47 A. M. Das and D. A. Harris, Biochim. Biophys. Acta, Mol. Basis Dis., 1991, 1096, 284-290.

48 E. Esfandiari, S. Roshankhah, M. Mardani, B. Hashemibeni, E. Naghsh, M. Kazemi and M. Salahshoor, Iran. J. Basic Med. Sci., 2014, 17, 571-576.

49 T. E. DeCoursey, Immunol. Rev., 2016, 273, 194-218.

50 M. Wartenberg, N. Wirtz, A. Grob, W. Niedermeier, J. Hescheler, S. C. Peters and H. Sauer, Bioelectromagnetics, 2008, 29, 47-54.

51 K. Srirussamee, S. Mobini, N. J. Cassidy and S. H. Cartmell, Biotechnol. Bioeng., 2019, 116, 3421-3432.

52 E. Serena, E. Figallo, N. Tandon, C. Cannizzaro, N. Elvassore and G. Vunjak-novakovic, Cell, 2010, 315, 3611-3619.

53 M. M. Lozano, J. S. Hovis, F. R. Moss and S. G. Boxer, J. Am. Chem. Soc., 2016, 138, 9996-10001.

54 B. J. Lin, S. H. Tsao, A. Chen, S. K. Hu, L. Chao and P. H. G. Chao, Proc. Natl. Acad. Sci. U. S. A., 2017, 114, 8568-8573.

55 T. Batista Napotnik, T. Polajžer and D. Miklavčič, Bioelectrochemistry, 2021, 141, 107871. 
56 G. Thrivikraman, G. Madras and B. Basu, Biomaterials, 2014, 35, 6219-6235.

57 B. Mercadal, N. Beitel-White, K. N. Aycock, Q. Castellví, R. V. Davalos and A. Ivorra, Ann. Biomed. Eng., 2020, 48, 1451-1462.

58 A. Gelmi and C. E. Schutt, Adv. Healthcare Mater., 2021, 10, 1-30.

59 F. Alvarado-Hidalgo, K. Ramírez-Sánchez and R. StarbirdPerez, Molecules, 2020, 25, 5286.

60 H. Nekounam, S. Gholizadeh, Z. Allahyari, H. Samadian, N. Nazeri, M. A. Shokrgozar and R. Faridi-Majidi, Mater. Res. Bull., 2021, 134, 111083.

61 I. Rocha, G. Cerqueira, F. Varella Penteado and S. I. Córdoba de Torresi, Front. Med. Technol., 2021, 3, 1-18.

62 S. Vijayavenkataraman, S. Kannan, T. Cao, J. Y. H. Fuh, G. Sriram and W. F. Lu, Front. Bioeng. Biotechnol., 2019, 7, 1-14.

63 S. Song, D. Amores, C. Chen, K. McConnell, B. Oh, A. Poon and P. M. George, Sci. Rep., 2019, 9, 19565.

64 R. Elashnikov, S. Rimpelová, L. Děkanovský, V. Švorčík and O. Lyutakov, J. Mater. Chem. B, 2019, 7, 6500-6507.

65 Y. Xu, Z. Huang, X. Pu, G. Yin and J. Zhang, Cell Proliferation, 2019, 52, 1-11.

66 Y. Li, X. Li, R. Zhao, C. Wang, F. Qiu, B. Sun, H. Ji, J. Qiu and C. Wang, Mater. Sci. Eng., C, 2017, 72, 106-112.

67 F. Ghorbani, B. Ghalandari, A. L. Khan, D. Li, A. Zamanian and B. Yu, Biotechnol. Prog., 2020, 36, 1-16.

68 Y. Arteshi, P. Mohammad Hoseinpour and S. Davaran, Mater. Today Proc., 2019, 42, 1579-1587.

69 D. Shan, S. R. Kothapalli, D. J. Ravnic, E. Gerhard, J. P. Kim, J. Guo, C. Ma, J. Guo, L. Gui, L. Sun, D. Lu and J. Yang, Adv. Funct. Mater., 2018, 28, 1801787.

70 M. Wang, P. L. Tremblay and T. Zhang, Bioelectrochemistry, 2021, 140, 107750.

71 H. Y. Gong, J. Park, W. Kim, J. Kim, J. Y. Lee and W. G. Koh, ACS Appl. Mater. Interfaces, 2019, 11, 47695-47706.

72 A. C. da Silva, R. A. da Silva, M. J. P. G. Souza, P. M. Montoya, R. Bentini, T. Augusto, R. M. Torresi, L. H. Catalani and S. I. Córdoba de Torresi, Biointerphases, 2020, 15, 021003.

73 S. Wang, S. Guan, W. Li, D. Ge, J. Xu, C. Sun, T. Liu and X. Ma, Mater. Sci. Eng., C, 2018, 93, 890-901.

74 S. Wang, S. Guan, Z. Zhu, W. Li, T. Liu and X. Ma, Mater. Sci. Eng., C, 2017, 71, 308-316.

75 J. Radwan-Pragłowska, Ł. Janus, M. Piątkowski, D. Bogdał and D. Matýsek, Polymers, 2020, 12, 159.

76 M. O. Oftadeh, B. Bakhshandeh, M. M. Dehghan and A. Khojasteh, J. Biomed. Mater. Res., Part A, 2018, 106, 1200-1210.

77 J. Radwan-Pragłowska, Ł. Janus, M. Piatkowski, D. Bogdał and D. Matysek, Polymers, 2020, 12, 792.

78 A. Abedi, B. Bakhshandeh, A. Babaie, J. Mohammadnejad, S. Vahdat, R. Mombeiny, S. R. Moosavi, J. Amini and L. Tayebi, Mater. Chem. Phys., 2021, 258, 123842.

79 R. Khalili, P. Zarrintaj, S. H. Jafari, H. Vahabi and M. R. Saeb, Int. J. Biol. Macromol., 2020, 154, 18-24.
80 S. Grossemy, P. P. Y. Chan and P. M. Doran, Integr. Biol., 2019, 11, 264-279.

81 B. Bagheri, P. Zarrintaj, A. Samadi, R. Zarrintaj, M. R. Ganjali, M. R. Saeb, M. Mozafari, O. O. Park and Y. C. Kim, Int. J. Biol. Macromol., 2020, 147, 160-169.

82 E. M. Steel, J. Y. Azar and H. G. Sundararaghavan, Materialia, 2020, 9, 100581.

83 A. Serafin, C. Murphy, M. C. Rubio and M. N. Collins, Mater. Sci. Eng., C, 2021, 122, 111927.

84 S. Homaeigohar, T. Y. Tsai, T. H. Young, H. J. Yang and Y. R. Ji, Carbohydr. Polym., 2019, 224, 115112.

85 E. M. Steel, J. Y. Azar and H. G. Sundararaghavan, Materialia, 2020, 9, 100581.

86 Y. Sun, X. Liu, M. N. George, S. Park, B. Gaihre, A. Terzic and L. Lu, J. Biomed. Mater. Res., Part A, 2021, 109, 193-206.

87 L. He, Q. Xiao, Y. Zhao, J. Li, S. Reddy, X. Shi, X. Su, K. Chiu and S. Ramakrishna, ACS Appl. Mater. Interfaces, 2020, 12, 53150-53163.

88 S. Mombini, J. Mohammadnejad, B. Bakhshandeh, A. Narmani, J. Nourmohammadi, S. Vahdat and S. Zirak, Int. J. Biol. Macromol., 2019, 140, 278-287.

89 M. Imaninezhad, K. Pemberton, F. Xu, K. Kalinowski, R. Bera and S. P. Zustiak, J. Neural Eng., 2018, 15, 56034.

90 Z. Liu, M. Yushan, Y. Alike, Y. Liu, S. Wu, C. Ma and A. Yusufu, Biomed. Res. Int., 2020, 4794982.

91 P. Hitscherich, A. Aphale, R. Gordan, R. Whitaker, P. Singh, L. Hua Xie, P. Patra and E. J. Lee, J. Biomed. Mater. Res., Part A, 2018, 106, 2923-2933.

92 G. Agarwal, N. Kumar and A. Srivastava, Mater. Sci. Eng., C, 2021, 118, 111518.

93 C. Zhang, S. Fan, H. Shao, X. Hu, B. Zhu and Y. Zhang, Carbon, 2019, 148, 16-27.

94 J. Zhu, Z. Qi, C. Zheng, P. Xue, C. Fu, S. Pan and X. Yang, J. Nanomater., 2020, 5892506.

95 C. Angulo-Pineda, K. Srirussamee, P. Palma, V. M. Fuenzalida, S. H. Cartmell and H. Palza, Nanomaterials, 2020, 10, 9-13.

96 J. Wang, Y. Cheng, L. Chen, T. Zhu, K. Ye, C. Jia, H. Wang, M. Zhu, C. Fan and X. Mo, Acta Biomater., 2019, 84, 98-113.

97 P. Fomby, A. J. Cherlin, A. Hadjizadeh, C. J. Doillon, V. Sueblinvong, D. J. Weiss, J. H. T. Bates, T. Gilbert, W. C. Liles, C. Lutzko, J. Rajagopal, D. J. Prockop, D. Chambers, A. Giangreco, A. Keating, D. Kotton, P. I. Lelkes, D. E. Wagner and D. J. Prockop, Ann. Am. Thorac. Soc., 2010, 12, 181-204.

98 T. Nezakati, A. Seifalian, A. Tan and A. M. Seifalian, Chem. Rev., 2018, 118, 6766-6843.

99 R. Balint, N. J. Cassidy and S. H. Cartmell, Acta Biomater., 2014, 10, 2341-2353.

100 R. Vidu, M. Rahman, M. Mahmoudi, M. Enachescu, T. D. Poteca and I. Opris, Front. Syst. Neurosci., 2014, 8, 1-24.

101 S. Bhattacharjee, R. Joshi, A. A. Chughtai and C. R. Macintyre, Adv. Mater. Interfaces, 2019, 6, 1-27.

102 T. J. Sisto, L. N. Zakharov, B. M. White and R. Jasti, Chem. Sci., 2016, 7, 3681-3688. 
103 W. Wang, Y. Hou, D. Martinez, D. Kurniawan, W. H. Chiang and P. Bartolo, Polymers, 2020, 12, 1-38.

104 N. Wanasingha, P. Dorishetty, N. K. Dutta and N. R. Choudhury, Gels, 2021, 7, 148.

105 J. P. S. Sagou, S. Ahualli and F. Thomas, J. Colloid Interface Sci., 2015, 459, 212-217.

106 S. De, A. Ostendorf, M. Schönhoff and C. Cramer, Polymers, 2017, 9, 1-16.

107 H. Li, A. Erbaş, J. Zwanikken and M. Olvera De La Cruz, Macromolecules, 2016, 49, 9239-9246.
108 C. J. Lee, H. Wu, Y. Hu, M. Young, H. Wang, D. Lynch, F. Xu, H. Cong and G. Cheng, ACS Appl. Mater. Interfaces, 2018, 10, 5845-5852.

109 A. Ostendorf, M. Schönhoff and C. Cramer, Phys. Chem. Chem. Phys., 2019, 21, 7321-7329.

110 C. Zuccato and E. Cattaneo, Nat. Rev. Neurol., 2009, 5, 311-322.

111 Z. Shariatinia, Adv. Colloid Interface Sci., 2019, 263, 131-194.

112 D. Zhao, S. Yu, B. Sun, S. Gao, S. Guo and K. Zhao, Polymers, 2018, 10, 462. 